\title{
Stratospheric Ozone Depletion: The Main Driver of Twentieth-Century Atmospheric Circulation Changes in the Southern Hemisphere
}

\author{
LORENZO M. POLVANI \\ Department of Applied Physics and Applied Mathematics, and Department of Earth and Environmental Sciences, \\ Columbia University, New York, New York \\ DARRYN W. WAUGH \\ Department of Earth and Planetary Sciences, The Johns Hopkins University, Baltimore, Maryland \\ Gustavo J. P. CORREA \\ Lamont-Doherty Earth Observatory, Columbia University, Palisades, New York \\ SEOK-WOO SON \\ Department of Atmospheric and Oceanic Sciences, McGill University, Montreal, Québec, Canada
}

(Manuscript received 6 April 2010, in final form 3 September 2010)

\begin{abstract}
The importance of stratospheric ozone depletion on the atmospheric circulation of the troposphere is studied with an atmospheric general circulation model, the Community Atmospheric Model, version 3 (CAM3), for the second half of the twentieth century. In particular, the relative importance of ozone depletion is contrasted with that of increased greenhouse gases and accompanying sea surface temperature changes. By specifying ozone and greenhouse gas forcings independently, and performing long, time-slice integrations, it is shown that the impacts of ozone depletion are roughly 2-3 times larger than those associated with increased greenhouse gases, for the Southern Hemisphere tropospheric summer circulation. The formation of the ozone hole is shown to affect not only the polar tropopause and the latitudinal position of the midlatitude jet; it extends to the entire hemisphere, resulting in a broadening of the Hadley cell and a poleward extension of the subtropical dry zones. The CAM3 results are compared to and found to be in excellent agreement with those of the multimodel means of the recent Coupled Model Intercomparison Project (CMIP3) and Chemistry-Climate Model Validation (CCMVal2) simulations. This study, therefore, strongly suggests that most Southern Hemisphere tropospheric circulation changes, in austral summer over the second half of the twentieth century, have been caused by polar stratospheric ozone depletion.
\end{abstract}

\section{Introduction}

The most prominent and robust feature of climate change in the Southern Hemisphere (SH) over the second half of the twentieth century is an increase in zonal mean sea level pressure difference between the mid and high latitudes, commonly referred to as an increase in the positive phase of the southern annular mode (SAM) index

Corresponding author address: Lorenzo M. Polvani, S. W. Mudd Bldg., Rm. 216, Columbia University, Mail Code 4701, New York, NY 10027.

E-mail:1mp@columbia.edu
(Thompson et al. 2000; Marshall 2003; Fogt et al. 2009). This positive SAM trend reflects a poleward shift of the midlatitude $\mathrm{SH}$ jet and the accompanying storm tracks (Archer and Caldeira 2008), the concomitant poleward shift of the edge of the Hadley circulation ( $\mathrm{Hu}$ and $\mathrm{Fu}$ 2007), and poleward expansion of the subtropical dry zones (Previdi and Liepert 2007).

The cause of these trends remains, however, unknown. Considering the seasonality of the observed trends, Thompson and Solomon (2002) suggested that stratospheric ozone depletion may be an important contributor. This has been borne out in a number of modeling studies spanning the whole spectrum of model 
complexity, from idealized dynamical cores, to coupled atmosphere-ocean models, to chemistry-coupled stratosphere-resolving models (Sexton 2001; Polvani and Kushner 2002; Gillett and Thompson 2003; Shindell and Schmidt 2004; Arblaster and Meehl 2006; Perlwitz et al. 2008; Son et al. 2009a, 2010).

On the other hand, many studies have shown that increasing greenhouse gases alone, in the absence of stratospheric ozone depletion (or recovery), also results in a poleward shift of the midlatitude jets, notably in the Southern Hemisphere (Fyfe et al. 1999; Kushner et al. 2001; Cai et al. 2003; Marshall et al. 2004; Shindell and Schmidt 2004; Arblaster and Meehl 2006). At present, the relative importance of stratospheric ozone depletion versus increasing greenhouse gases remains unclear.

The Coupled Model Intercomparison Project (CMIP3) model integrations (Meehl et al. 2007a) have provided some evidence that stratospheric ozone depletion may be a major player in $\mathrm{SH}$ climate change. Approximately half the CMIP3 models did not include the significant observed changes in polar stratospheric ozone in the $\mathrm{SH}$ in the simulations of twentieth-century climate (20C3M). Taking advantage of this, several studies have shown that $\mathrm{SH}$ atmospheric circulation changes in the CMIP3 model simulations that did include stratospheric ozone depletion are much larger than for the models that did not (Cai and Cowan 2007; Karpechko et al. 2008; Son et al. 2009a).

However, since the ozone fields used by the CMIP3 models were not archived, and since different models used different stratospheric ozone fields, a quantitative estimate of the relative importance of stratospheric ozone depletion on $\mathrm{SH}$ climate cannot be directly extracted from the CMIP3 dataset. More importantly, in addition to using different ozone fields, individual CMIP3 model simulations also included a variety of different forcings, such as black carbon, volcanic aerosols, dust, etc. (see Table 10.1 in Meehl et al. 2007b). It is thus impossible, in the CMIP3 dataset, to untangle the climate impacts due to stratospheric ozone depletion from those due to other climate forcings. Hence the need for this study.

In this paper we aim to show that stratospheric ozone depletion has been, in fact, the dominant forcing of the SH climate system in the twentieth century. We demonstrate this by performing single-forcing model integrations, specifically contrasting the amplitude of a model response to ozone depletion to that resulting from increasing greenhouse gases. In many ways our study builds on the previous work of Shindell and Schmidt (2004) and Arblaster and Meehl (2006). One key difference is that all model forcings in our study-notably the sea surface temperatures and sea ice concentrations (hereafter referred to as SSTs, for the sake of brevity), but also the ozone fields and the greenhouse gas concentrations-are taken from observations. Hence, subject to the model's ability to simulate the atmospheric circulation accurately, the model response to different observed forcings can be interpreted directly in terms of their relative, quantitative, importance.

A second difference from previous work is that we here integrate the model in "time slice" configuration (i.e., with seasonally varying forcings that have no year-to-year trends). As shown below, the interannual variability for several key aspects of the atmospheric circulation is large and, in fact, comparable in magnitude to the responses we are trying to compute. Eliminating transient behavior allows us to establish that, in December-February (DJF), the model response is statistically different from the model's interannual variability only when the model is forced with stratospheric ozone depletion. This is a key result of our paper.

Finally, it may be useful to note that our study is, in some sense, a follow-up to the recent paper of Deser and Phillips (2009, hereafter referred to as DP09). In that paper, using an atmospheric general circulation model with independently prescribed SSTs and radiative forcings, the distinct contributions of each of these to latetwentieth-century climate changes were made clear. In a nutshell, DP09 show that circulation changes in the Northern Hemisphere can be directly attributed to SST changes, whereas SH circulation changes are only weakly affected by SSTs and are controlled, rather, by direct atmospheric radiative forcings. In this paper we ask: Which of these radiative forcings matters most? By prescribing ozone and greenhouse gases independently, we show that stratospheric ozone depletion is the likely dominant cause of $\mathrm{SH}$ circulation changes in the twentieth century, overwhelming by a factor of 2-3 the changes induced by increasing greenhouse gases over the period 1960-2000.

\section{Methods}

\section{a. The model}

The numerical model used in this study is the Community Atmospheric Model, version 3 (CAM3). Its numerical and physical setup is fully documented in Collins et al. (2006), and its climate characteristics have been reported in some detail (Hurrell et al. 2006; Hack et al. 2006). For this study, CAM 3 is run at T42 horizontal resolution (roughly equivalent a $2.8^{\circ} \times 2.8^{\circ}$ grid) and with the standard configuration of 26 hybrid vertical levels, 8 of which are located above $100 \mathrm{hPa}$, and with the model top at $2.2 \mathrm{hPa}$. The model is forced by specifying 1) prescribed sea surface temperatures and sea ice concentrations, 2) zonal-mean latitude-height ozone fields, and 
TABLE 1. The model integrations used in this study and their respective forcings. In all cases, the models are integrated for $50 \mathrm{yr}$ in a time-slice configuration (i.e., SSTs and forcings have a seasonal cycle, but no year-to-year trends). All forcings other than those specified here (e.g., solar constant) are identical in all model integrations.

\begin{tabular}{lcccccrr}
\hline \hline Integration & Ozone (yr) & SSTs (avg range) & $\mathrm{CO}_{2}\left(\times 10^{-6}\right)$ & $\mathrm{CH}_{4}\left(\times 10^{-9}\right)$ & $\mathrm{N}_{2} \mathrm{O}\left(\times 10^{-9}\right)$ & $\mathrm{CFC}-11\left(\times 10^{-12}\right)$ & $\mathrm{CFC}-12\left(\times 10^{-12}\right)$ \\
\hline REF1960 & 1960 & $1952-1968$ & 317 & 1271 & 291 & 9 & 30 \\
OZONE2000 & 2000 & $1952-1968$ & 317 & 1271 & 291 & 9 & 30 \\
GHG2000 & 1960 & $1992-2008$ & 369 & 1761 & 316 & 262 & 540 \\
BOTH2000 & 2000 & $1992-2008$ & 369 & 1761 & 316 & 262 & 540 \\
\hline
\end{tabular}

3) individual numbers for the concentration of wellmixed greenhouse gases. For all other forcings we use the model default values (e.g., the solar constant is set to $1367 \mathrm{~W} \mathrm{~m}^{-2}$ ). The model is run in time-slice configuration, that is, with the only time dependence of the forcings being the seasonal cycle in SSTs and ozone. The initial conditions are taken from the official CAM3 release dataset and correspond to the first day of September of an arbitrary year.

\section{b. The forcings}

The sea surface temperatures and sea ice concentrations we have used for this study are those of the Hadley Centre dataset (Rayner et al. 2003). These observed SSTs were chosen, among other reasons, because they have been used as forcing for the Chemistry-Climate Model Validation intercomparison projects (CCMVal and CCMVal2), which form the basis of the 2006 and 2011 World Meteorological Organization (WMO) ozone assessment reports (Eyring et al. 2006, 2010). Among other objectives, the present study aims at contrasting, in terms of the response to stratospheric ozone depletion, those models with an Intergovernmental Panel on Climate Change (IPCC) class atmospheric general circulation model, that is, one without a fully resolved stratospheric circulation or interactive stratospheric chemistry. Using identical SSTs allows for a more meaningful quantitative comparison. Of course, a number of caveats apply when specifying SSTs and inferring circulation changes in an atmosphere-only general circulation model; see DP09 for a concise discussion of the relevant issues.

The ozone fields used in this study (I. Cionni et al. 2010, unpublished manuscript) are taken from the dataset assembled by a joint Atmospheric Chemistry and Climate and Stratospheric Processes and their Role in Climate (SPARC) committees of the World Climate Research Programme (WCRP), for the upcoming CMIP5 model intercomparison project We will refer to it here as the SPARC ozone dataset. This dataset consists of monthly mean, zonal mean ozone fields over the period 1850-2100. For the historical part of interest here (i.e., before 2008), the stratospheric ozone field in this dataset is constructed from satellite observations and polar ozonesonde measurements, as described in Randel and $\mathrm{Wu}(2007)$, extended backward from 1979 to 1850 via regression fits combined with extended proxy time series. The stratospheric ozone data are then blended across the climatological tropopause with tropospheric ozone data obtained from a combination of chemistry-climate model integrations. For the present purpose, what matters is the difference in stratospheric polar ozone before and after the SH ozone hole formation: for this, the SPARC ozone dataset constitutes the most accurate combination of observations currently available.

The greenhouse gas concentrations used in this study are as follows. In its simplest configuration, which we have adopted here, CAM3 allows one to control the levels of carbon dioxide, methane, nitrous oxide, and two chlorofluorocarbons (CFC-11 and CFC-12) by specifying their concentration via a single number, which is then applied uniformly in time and space for the evaluation of the radiative forcing, under the assumption that these gases are well mixed throughout the entire atmosphere. For $\mathrm{CO}_{2}, \mathrm{CH}_{4}$, and $\mathrm{N}_{2} \mathrm{O}$, we take values from the Special Report on Emissions Scenarios (SRES) A1B scenario (Nakicenovic et al. 2000). For CFC-11 and CFC-12, we take values from the A1 scenario constructed for the 2002 Scientific Assessment of Ozone Depletion (WMO/ UNEP 2003).

\section{c. The integrations}

In this paper we will be discussing four, 50-yr-long, time-slice integrations, labeled according to the forcings used: these are presented in Table 1 . The reference integration is labeled REF1960: it is forced with SSTs from the Hadley Centre dataset, averaged over the 17-yr period 1952-68, with SPARC ozone taken from the year 1960, and with greenhouse gases also taken from the datasets mentioned above for the year 1960. The idea is to integrate the climate model with all forcings fixed at 1960 levels, that is, before the formation of the $\mathrm{SH}$ ozone hole.

To determine quantitively the effects of stratospheric ozone depletion, this reference integration is contrasted with the one labeled OZONE2000, which is identical to the reference integration in all respects, except for the ozone fields, which are taken from the year 2000 of the 
a: $(2000-1960)$ SPARC ozone at $50 \mathrm{hPa}$

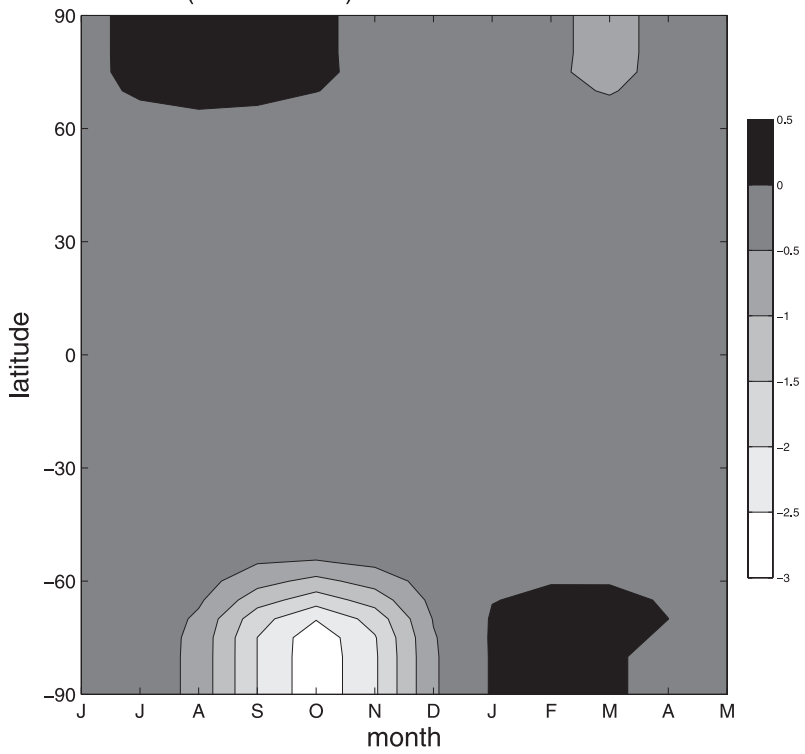

b: $(2000$ - 1960) polar cap SPARC ozone

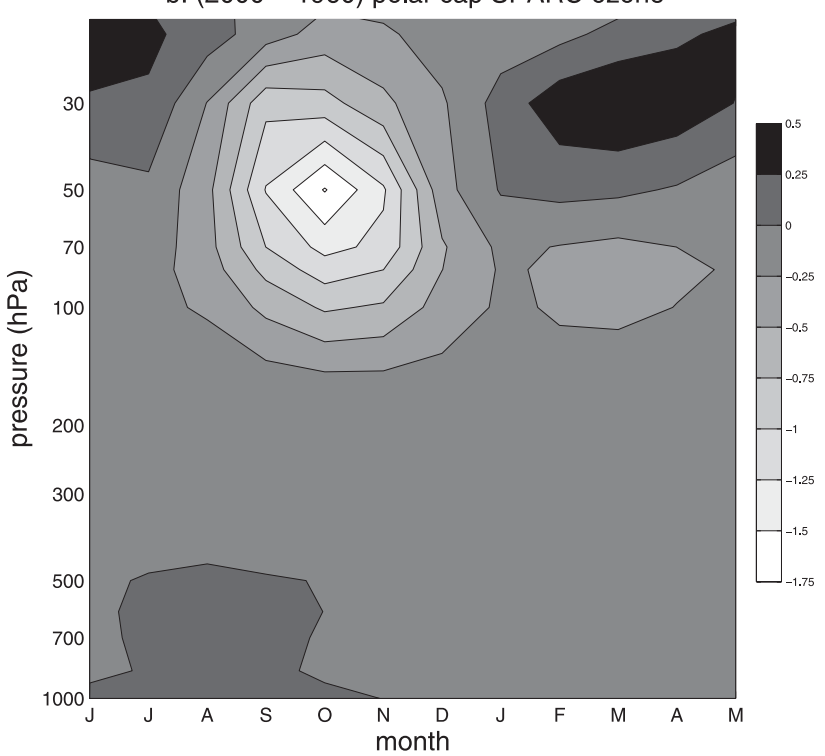

FIG. 1. The horizontal and vertical extents of the ozone hole used in the study, from the SPARC ozone dataset. (left) Latitudinal cross section at $50 \mathrm{hPa}$. (right) Vertical extent over the polar cap (defined as the area south of of $65^{\circ} \mathrm{S}$ ). Units are ppmv. The ozone hole is the prominent white area in both panels.

SPARC ozone dataset. Note that, in this integration, we leave the halocarbons at 1960 levels, which might appear inconsistent. However, the key point of this paper is to show the importance of stratospheric ozone depletion: this is why we leave all other forcings untouched, to avoid any unnecessary complications. In any case, the greenhouse effects of CFCs are very small, when compared with those of the major greenhouse gases.

To contrast the relative effects of ozone depletion with those of greenhouse gas increases, a third integration labeled GHG2000 is performed, with all forcings at year 2000 levels, except for ozone, which is left at 1960 levels. Note that the SSTs in this integration are also averaged over a 17-yr period, specifically 1992-2008 (the Hadley Centre SSTs being available only up to 2008 at the time this work was performed). The idea here is to quantify the response of the model to the greenhouse gas increase alone, including the fact that SSTs warm up as a consequence of that increase, but in the nearly ${ }^{1}$ complete absence of the ozone depletion.

\footnotetext{
${ }^{1}$ It is conceivable that ozone depletion might also affect the SSTs, but it is reasonable to believe that such an effect would be relatively small in comparison to the one induced by increasing greenhouse gases. This paper, therefore, is concerned with what might be called the direct effect of ozone depletion. An indirect effect-mediated by the changing of SSTs due to ozone depletionmay exist, but is likely to be small, as reported in the recent study of Sigmond et al. (2010).
}

Finally, to evaluate the linearity of the response, we perform an integration in which all forcings are set at year 2000 levels; this integration is labeled BOTH2000. As we will show below, for some features of the atmospheric circulation the model's response is somewhat (though not always) linear and, where so, caused to a large extent by ozone depletion.

One final note about the forcings used in this study. Since the Hadley Centre SSTs are widely used, we do not show here the difference between the 1952-68 and the 1992-2008 averages. However, the SPARC ozone dataset is relatively new (in fact, it has not been used in any model integrations we are aware of), and so we illustrate the physical extent of the ozone hole that is at the basis of this study. In Fig. 1 its seasonal, vertical, and latitudinal characteristics (as represented in the SPARC dataset) are shown. Three items are worthy of note. First, while the SH ozone minimum peaks in October, the depletion (and thus the accompanying direct thermal effect in the lower stratosphere) lasts for several months, roughly from September to November. Second, the latitudinal extent, though confined largely to the $\mathrm{SH}$, spans nearly $30^{\circ}$ of latitude, from the South Pole to almost $60^{\circ} \mathrm{S}$. Third, the bulk of the ozone hole is in the lowermost stratosphere, with the depletion extending down below $100 \mathrm{hPa}$. Since ozone depletion over the $\mathrm{SH}$ polar cap is of very large amplitude, has a broad latitudinal extent, lasts for several months, and is located just above the tropopause, one might expect it to have 
a: OZONE2000 - REF1960

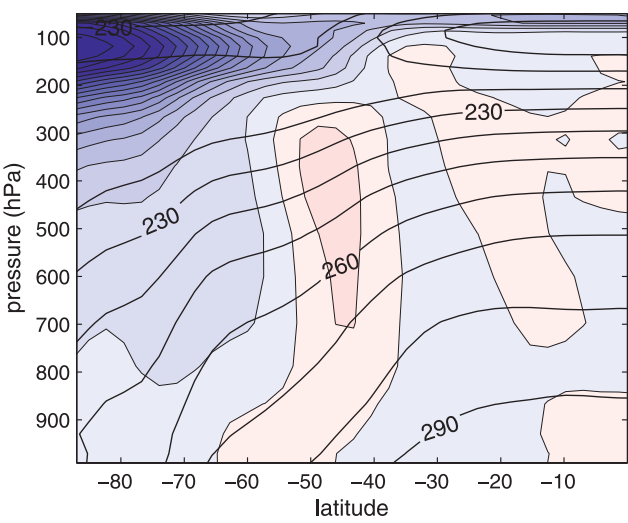

c: BOTH2000 - REF1960

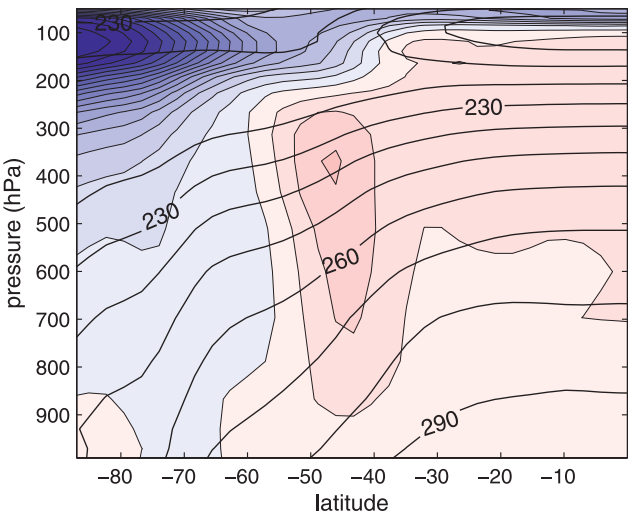

b: GHG2000 - REF1960

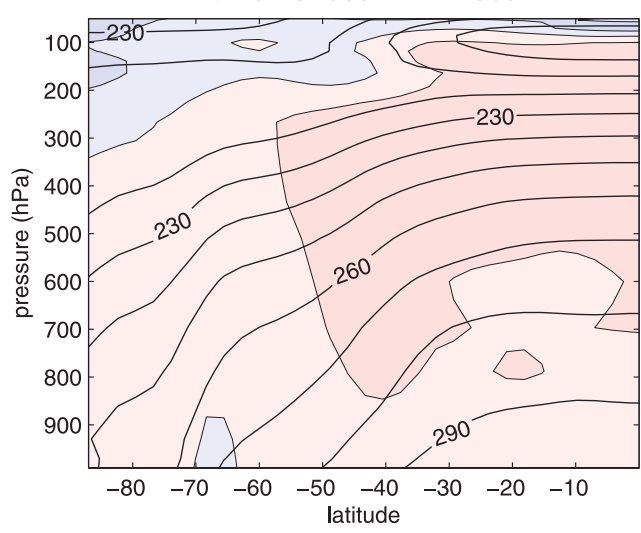

$\mathrm{d}: \mathrm{c}-\mathrm{a}$

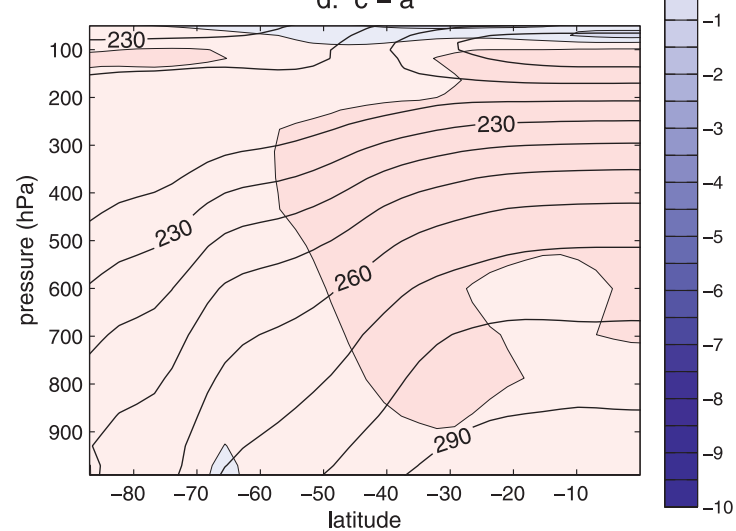

FIG. 2. Colored contours show the DJF temperature differences between the REF1960 integration and the (a) OZONE2000, (b) GHG2000, and (c) BOTH2000 integrations. (d) The difference between (a) and (c), which should be contrasted with (b). In all panels the contour interval is $0.5 \mathrm{~K}$. Black contours show the zonal mean, time mean, DJF temperature for the REF1960 integration, with contour intervals of $10 \mathrm{~K}$.

a profound influence on the tropospheric circulation, as we describe next.

\section{Results}

\section{a. Atmospheric temperature and tropopause response}

We start by examining the thermal response of the model in Fig. 2, where the latitude-pressure, 50-yr mean, DJF profiles of temperature differences between the REF1960 control integration and OZONE2000, GHG2000, and BOTH2000 are shown, in panels a-c, respectively. In this, and all subsequent figures, we focus on the DJF response to the prescribed forcings. Although the ozone depletion occurs in September-November (SON) at about $50 \mathrm{hPa}$ (see Fig. 1b above), the tropospheric response is strongest in DJF, due to a lag of about a month or two for the stratospheric signal to propagate down (see, e.g., Fig. 1 of Son et al. 2008).

The key point of Fig. 2 is to illustrate the simple fact that the temperature response to stratospheric ozone depletion, while confined to the lower-stratospheric polar cap, is roughly 10 times larger than the one associated with greenhouse gas increases, over the period 19602000. The maximum cooling in Fig. 2a is a remarkable $-9.5 \mathrm{~K}$ (around $100 \mathrm{hPa}$ ), while the warming due to greenhouse gas increases, though broadly spread throughout the whole troposphere, never exceeds $1 \mathrm{~K}$. Notice also how the high-latitude stratospheric cooling associated with greenhouse gas increases is tiny (less than $1 \mathrm{~K}$ ) compared with the one caused by ozone depletion. Also, from the similarity of Fig. 2d, where the difference between the OZONE2000 and BOTH2000 integrations are shown, to Fig. $2 \mathrm{~b}$ one can conclude that the temperature response of our model is roughly linear, except in the polar stratosphere.

We also note that the dramatic cooling of the lower polar stratosphere that accompanies ozone depletion as computed with CAM3 in the time-slice integrations presented here is very similar to the rates of cooling computed in the recent set of CCMVal2 simulations (Son et al. 2010), and in the CMIP3 integrations, which 
TABLE 2. Atmospheric circulation response for the CAM integrations presented in the paper, and for the multimodel ensemble mean of the CCMVal2 and CMIP3 model simulations, over the period 1960-2000. For the CAM integrations, we report the differences from the REF1960 integration; for the CMIP3 and CCMVal2 simulations, we first compute the 1960-2000 linear trend, and then multiply by 40 , as described in Fig. 4 of Son et al. (2010). The polar cap cooling is the difference in the ONDJ zonal mean temperature at $100 \mathrm{hPa}$, averaged from $65^{\circ} \mathrm{S}$ to the South Pole. The tropopause raising is the difference in the DJF tropopause pressure, averaged from $65^{\circ} \mathrm{S}$ to the South Pole. The jet shift is the difference in the DJF latitude of the maximum of the zonal mean, zonal wind at $850 \mathrm{hPa}$. The Hadley cell edge shift is the DJF latitude difference in the zero of the mean meridional streamfunction at $500 \mathrm{hPa}$.

\begin{tabular}{lcccc}
\hline \hline Integration & $\begin{array}{c}\text { Polar cap } \\
\text { cooling } \\
(\mathrm{K})\end{array}$ & $\begin{array}{c}\text { Tropopause } \\
\text { raising } \\
(\mathrm{hPa})\end{array}$ & $\begin{array}{c}\text { Midlatitude } \\
\text { jet shift } \\
\left({ }^{\circ} \text { lat }\right)\end{array}$ & $\begin{array}{c}\text { Hadley } \\
\text { cell edge } \\
\text { shift }\left({ }^{\circ} \text { lat }\right)\end{array}$ \\
\hline OZONE2000 & -8.3 & -17.4 & -1.9 & -1.0 \\
GHG2000 & -0.35 & -2.3 & -0.74 & -0.50 \\
BOTH2000 & -7.5 & -17.3 & -2.1 & -1.2 \\
CCMVal2 & -7.9 & -16.4 & -2.0 & -0.87 \\
CMIP3 & -7.2 & -15.5 & -1.7 & -0.58 \\
\hline
\end{tabular}

did include ozone depletion (Son et al. 2009a). We find that the polar cap above the tropopause [in OctoberJanuary (ONDJ) at $100 \mathrm{hPa}$ ] cools by $-7.5 \mathrm{~K}$ in the BOTH2000 integration; this compares well with a corresponding cooling of $-7.9 \mathrm{~K}$ in the CCMVal2 simulations, and of $-7.2 \mathrm{~K}$ in the CMIP3 simulations (the latter are calculated by first computing the 1960-2000 multimodel trends, and then multiplying by 40 ). Also, as summarized in Table 2, the cooling in the BOTH2000 integration is not the sum of the coolings in the OZONE2000 and the GHG2000 integrations, indicating some nonlinearity in the polar cap thermal response, as already mentioned.

While the large thermal response to ozone depletion in the lower polar stratosphere is substantial, it is important to note that the surface temperature response to ozone depletion in our model is minuscule, in contrast with the surface temperature response to greenhouse gas increases: this can be seen in Figs. 2a and 2b. Quantitatively, for the GHG2000 integration the global mean surface temperature response of the model is a warming of $0.4 \mathrm{~K}$, which is broadly in line with the observations (Trenberth et al. 2007), whereas the surface temperature response to ozone depletion is nearly nonexistent $(0.01 \mathrm{~K}$ in our OZONE2000 integration), as one would expect. Of course some caveats are in order here, as SSTs are being specified in this model and hence surface temperatures may not be able to fluctuate as naturally as they would in a fully coupled atmosphere-ocean model. Nonetheless, the point here is that the influence of ozone depletion on SH circulation does not come from radiative changes near the surface, but from a top-down series of effects starting in the lower stratosphere, as detailed below.

It should not be surprising that the large, lowerstratospheric temperature anomalies caused by polar ozone depletion would have a direct impact on the height of the tropopause itself, as has already been reported in Son et al. (2009b). For the CAM integrations discussed here, the tropopause responses are illustrated in Fig. 3. We compute the tropopause from the zonal mean temperature fields using the standard definition (WMO a: OZONE2000

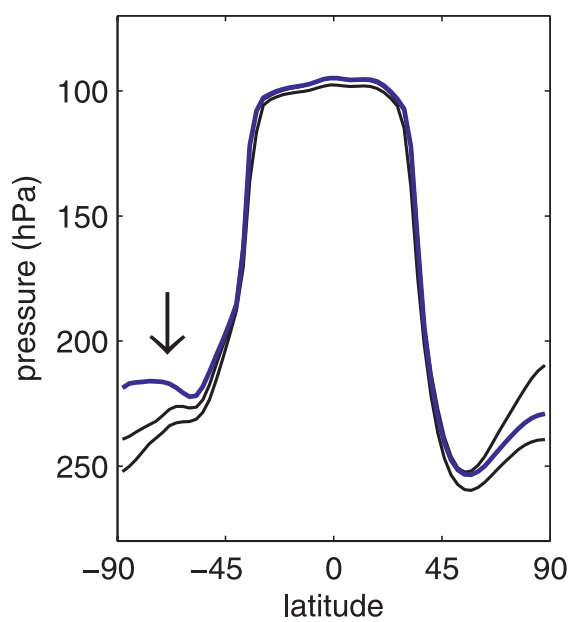

b: GHG2000

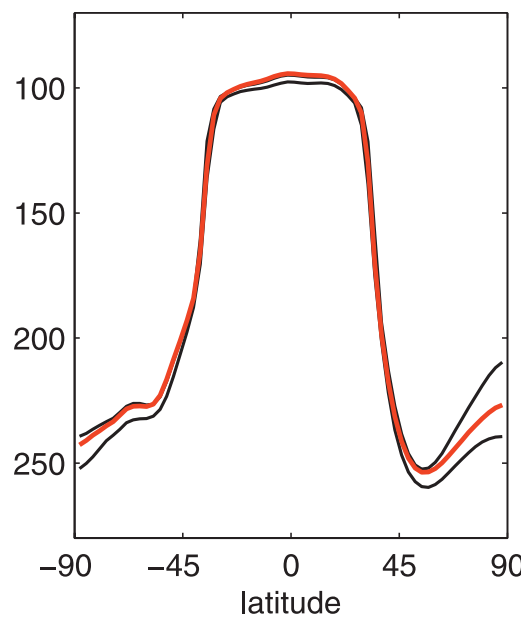

c: BOTH2000

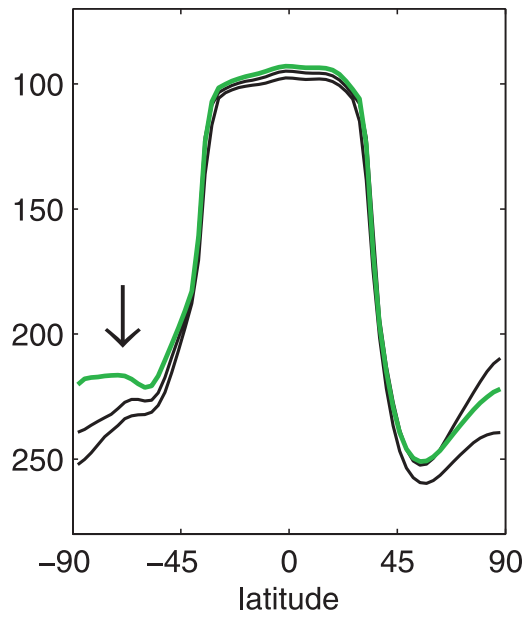

FIG. 3. Colored lines show the zonal mean, time mean tropopause pressure for the (a) OZONE2000, (b) GHG2000, and (c) BOTH2000 integrations. In all panels the two black lines indicate the interannual variability of the tropopause in the REF1960 integration, defined as the zonal mean, time mean tropopause \pm 1 standard deviation. 

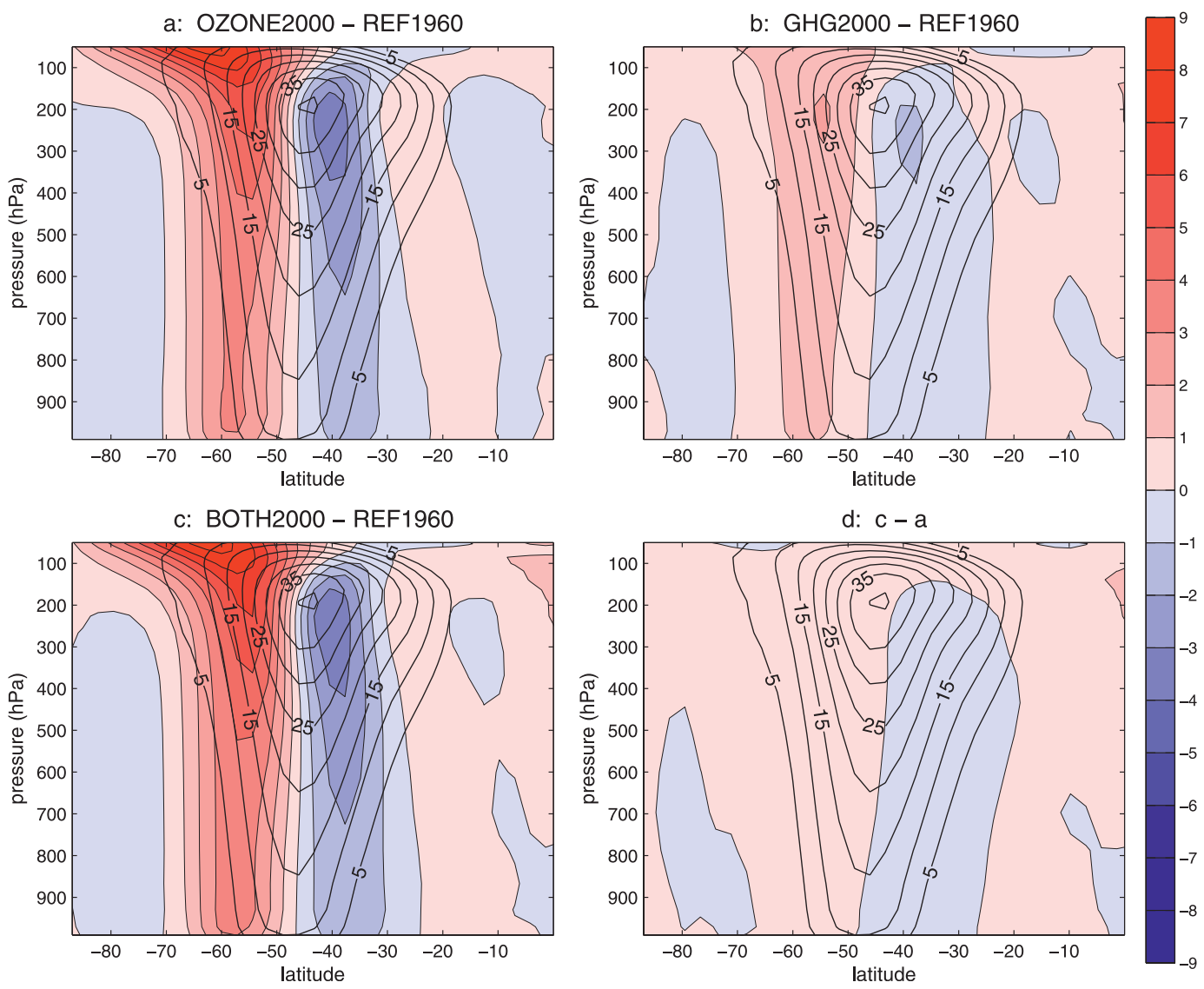

FIG. 4. As in Fig. 2, but for the zonal wind component. In all panels the contour interval is $1 \mathrm{~m} \mathrm{~s}^{-1}$. Black contours show the zonal mean, time mean, DJF zonal winds for the REF1960 integration, with contour intervals of $5 \mathrm{~m} \mathrm{~s}^{-1}$.

1957), following the algorithm proposed by Reichler et al. (2003). For the sake of clarity, the time mean, zonal mean, DJF tropopause height versus latitude is shown separately for each of the OZONE2000, GHG2000, and BOTH2000 integrations. In each panel in Fig. 3, the black lines mark the upper and lower bounds of the yearto-year range of the DJF tropopause height in the REF1960 integration (defined as the time mean value plus and minus one standard deviation).

As indicated by the black arrows in Figs. 3a and 3c, ozone depletion causes the $\mathrm{SH}$ polar tropopause to rise substantially, by more than $-17 \mathrm{hPa}$. This large value is not an anomaly of our model integrations, as it agrees very well with both the CCMVal2 and CMIP3 results (see Table 2). In contrast, for the GHG2000 integration, there is only a very weak lifting of the SH polar tropopause (smaller than a standard deviation), as can be seen in Fig. 3b. As a further validation of the model integrations, observe that the polar cap tropopause in the Northern Hemisphere remains well within the bounds of the reference integration, irrespective of forcing, as one might expect. Finally, we note that the lifting of the polar tropopause caused by ozone depletion is many times larger than the ones that have been reported for the global tropopause, which is typically of the order only a few hectopascals (Santer et al. 2003). This, again, suggests that the ozone depletion signal is much larger than the one associated with greenhouse gas increases. Contrary to naïve expectations, moreover, the model response to ozone depletion is not confined to the polar regions, but rather extends throughout the entire Southern Hemisphere, as we show next.

\section{b. Midlatitude jet and annular mode response}

Accompanying the substantial lifting of the SH polar tropopause, we find that the entire midlatitude jet shifts poleward, as illustrated in Fig. 4, where the DJF zonal mean, zonal wind differences from the reference integrations are presented (the solid black contours in each panel indicate the zonal mean, zonal wind for the REF1960 integration). A simple visual inspection should make it clear that the shift associated with polar ozone depletion is considerably larger than the one associated with greenhouse gas increases. For instance, in the GHG2000 
a: OZONE2000 (blue) and REF1960 (black)

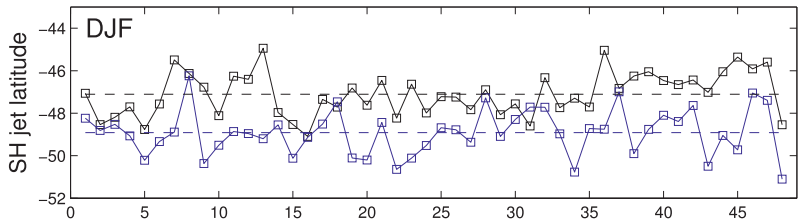

b: GHG2000 (red) and REF1960 (black)

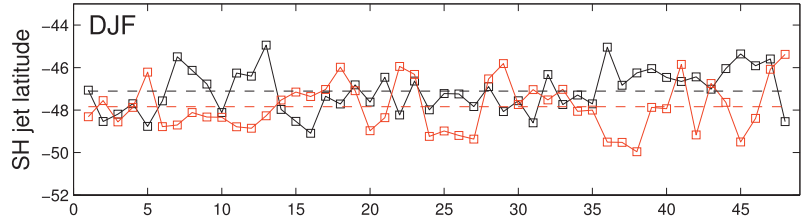

c: BOTH2000 (green) and REF1960 (black)

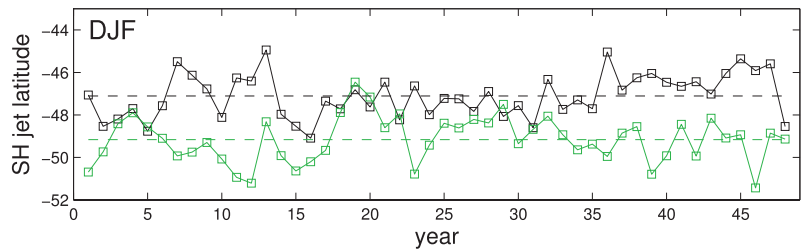

d: OZONE2000 (blue) and REF1960 (black)

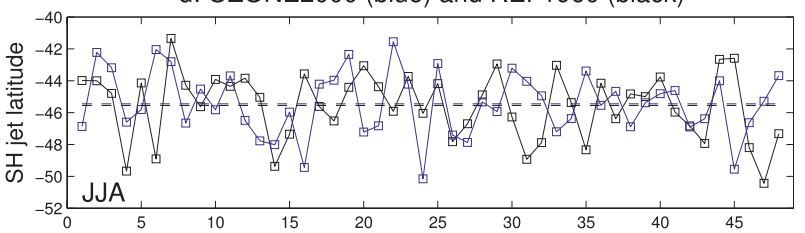

e: GHG2000 (red) and REF1960 (black)

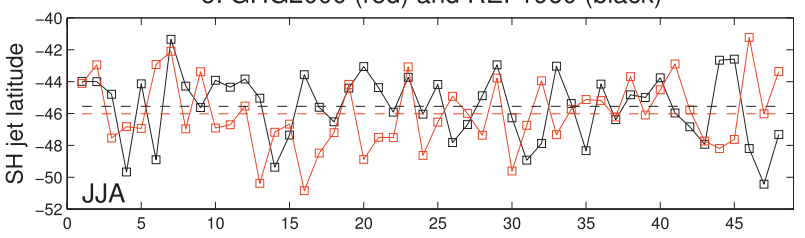

f: BOTH2000 (green) and REF1960 (black)

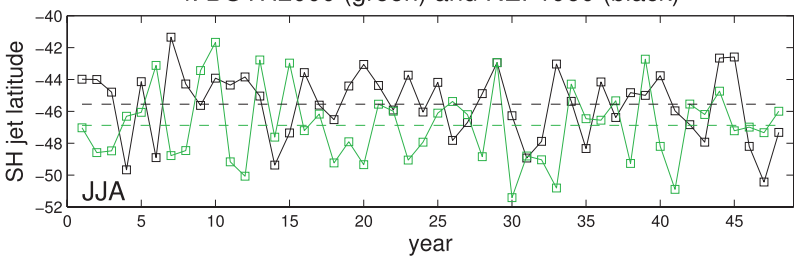

FIG. 5. Time series of the latitude of the 850-hPa zonal wind maximum, contrasting the REF1960 integration (black lines) with the (top) OZONE2000, (middle) GHG2000, and (bottom) BOTH2000 integrations, for (left) DJF and (right) JJA. Note that the axes on the ordinates are different. The dashed line shows the 50-yr time mean for each time series.

integration, the largest wind response is an acceleration of the westerlies, roughly $10^{\circ}$ poleward of the jet maximum near $200 \mathrm{hPa}$, with an amplitude of $2.1 \mathrm{~m} \mathrm{~s}^{-1}$; at the same height, the response in the OZONE2000 integration is $5.4 \mathrm{~m} \mathrm{~s}^{-1}$. The response to ozone depletion is even larger at $100 \mathrm{hPa}$ and above, as one might expect.

More important, however, is the fact that the poleward jet shift is not confined to the upper troposphere but propagates all the way to the surface in a surprisingly robust fashion. Although the surface wind response to stratospheric ozone depletion has been noted previously, we here show explicitly how it compares, quantitatively, to the response of increasing greenhouse gases, over the period 1960-2000, during which most of the ozone depletion has occurred. Contrasting Figs. $4 \mathrm{a}$ and $4 \mathrm{~b}$ strongly suggests that the observed SH shifts in the midlatitude jet in the second half of the twentieth century have been caused largely by ozone depletion, the contribution due to increasing greenhouse gases being considerably smaller. Note, in addition, that the response to the combined forcings (Fig. 4c) is not dramatically different from the one resulting from ozone depletion alone (Fig. 4a), as the response is qualitatively though not quantitatively linear (as already noted).

One might ask, at this point, to what degree the surface wind signature of stratospheric ozone depletion is statistically significant, given that the signal appears to decay away from the forcing region in the lower stratosphere.
To determine this, we plot, in the left column in Fig. 5, the DJF time series of the latitude of the zonal wind maximum at $850 \mathrm{hPa}$ in the $\mathrm{SH}$, for all three forced integrations. In all panels in Fig. 5, the black curves show the REF1960 integrations, and the colored lines show the forced responses. Notice how in Figs. 5a and 5c, where stratospheric ozone depletion is included, the jet latitude is consistently poleward of the reference integration, by about $2^{\circ}$ of latitude. Also note how the interannual variability is relatively large, typically of the same order of the shift we are trying to determine: hence the need for relatively long integrations, even in time-slice mode.

In contrast, the jet shift resulting from forcing the model with SSTs and GHG concentrations alone (Fig. 5b) does not show a good degree of separation from the reference integration, and in that case the $850-\mathrm{hPa}$ shift in the midlatitude $\mathrm{SH}$ jet is smaller than the standard deviation of the REF1960 time series. As a further validation that the statistically significant shift in the OZONE2000 and BOTH2000 integration is caused by stratospheric ozone depletion, we plot the corresponding June-August (JJA) time series in the right column of Fig. 5. No difference between the forced and reference integrations can be seen during those months, as expected.

Previous analyses of the CCMVal2 and CMIP3 models (Son et al. 2008, 2009a, 2010) have shown the existence of a roughly linear relationship between the lower-stratospheric temperature trends (due largely to ozone depletion) and 
a

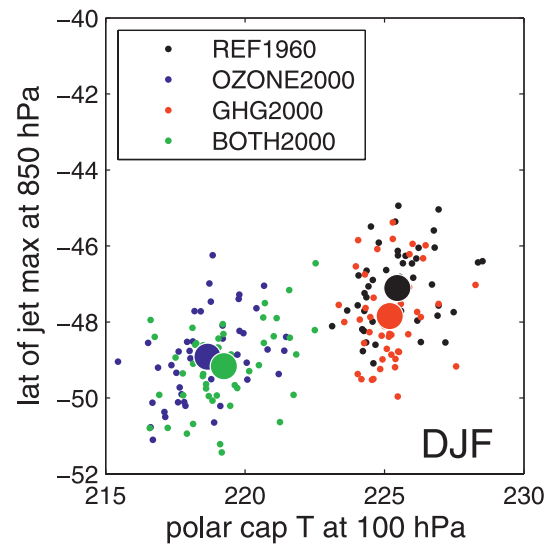

d

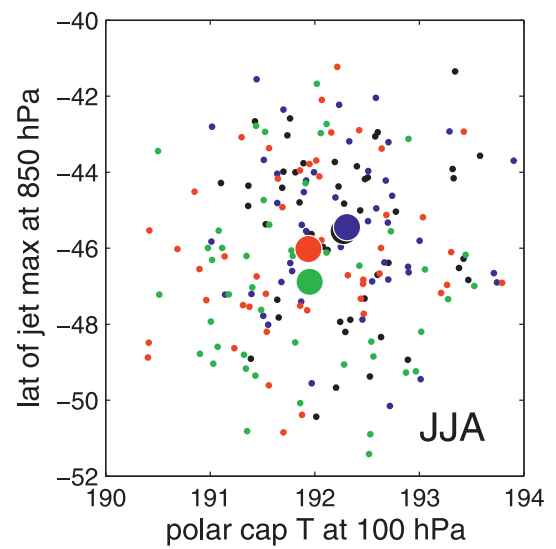

b

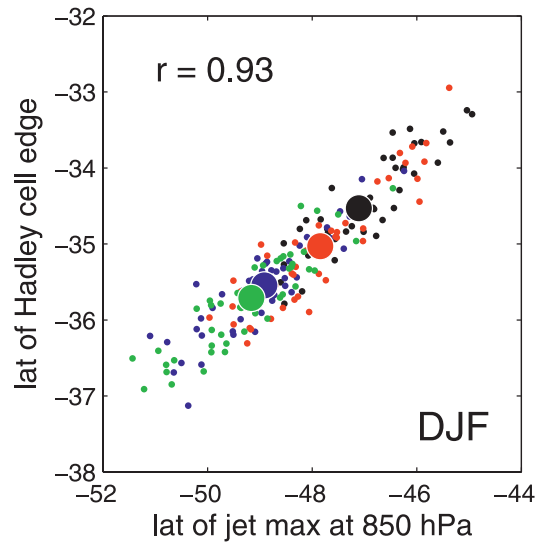

e

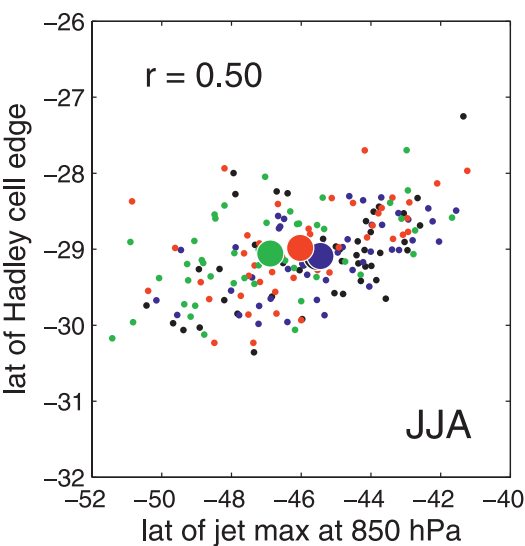

C

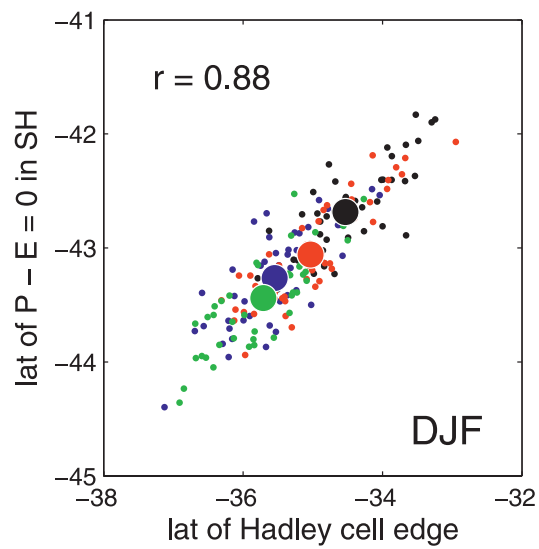

f

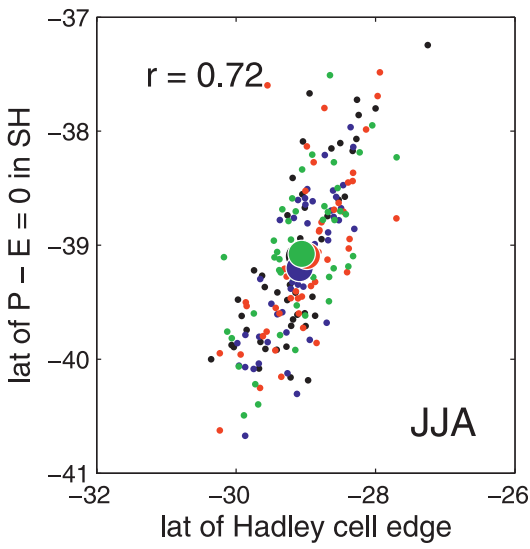

FIG. 6. Scatterplots of (left) polar cap temperature at $100 \mathrm{hPa}$ vs the latitude of the jet maximum at $850 \mathrm{hPa}$, (middle) the latter vs the latitude of the Hadley cell edge in the SH, and (right) the latter vs the latitude of $P-E=0$, for (top) DJF and (bottom) JJA. Small dots show individual years, and large dots the 50-yr average. Colors refer to different model integrations, as indicated in the legend.

the trends in the latitudinal location of the midlatitude jet. We can see this in our time-slice integrations as well, as illustrated in Fig. 6a, where we plot the latitude of the 850-hPa maximum zonal winds versus the mean polar cap temperature at $100 \mathrm{hPa}$. The four large dots, representing the 50-yr means of the four integrations, fall on the straight line, the integrations with ozone depletion (blue and green) exhibiting a cooler lower-stratospheric polar cap and a correspondingly poleward shifted midlatitude jet in the $\mathrm{SH}$, and being well separated from the integrations without ozone depletion (black and red). The corresponding JJA plot (Fig. 6d) shows no correlation between polar cap temperature and jet location, as expected.

More surprisingly, however, and not previously reported, is the fact that the polar cap temperatures and the jet location do not appear to be correlated on interannual time scales. In Fig. 6a, observe how the small dots (each one representing a different year) scatter as a cloud about the correspondingly colored large dot (representing the 50-yr mean). We are not sure how to interpret this result. We note, however, that the appearance of easterlies (i.e., the "final warming" of the polar vortex) in the SH occurs around mid-December at $50 \mathrm{hPa}$ (see, e.g., Fig. 2 of Eyring et al. 2006). Hence, the interannual variability in polar cap temperatures might simply reflect the variability in the date of the final warming. Recent studies have documented a clear stratospheric influence of final warmings on the tropospheric circulation in the Northern Hemisphere (Black et al. 2006; Black and McDaniel 2007), and a similar mechanism might be at play in the SH. Nonetheless, this lack of correlation between polar cap temperatures and the jet location on interannual time scales again points to the need for long integrations, such as the one we have performed here. Similarly, it suggests that relatively large ensemble integrations may be needed when the forcings are made time dependent from year to year, as the results of a small number of model runs would likely not be statistically significant. 

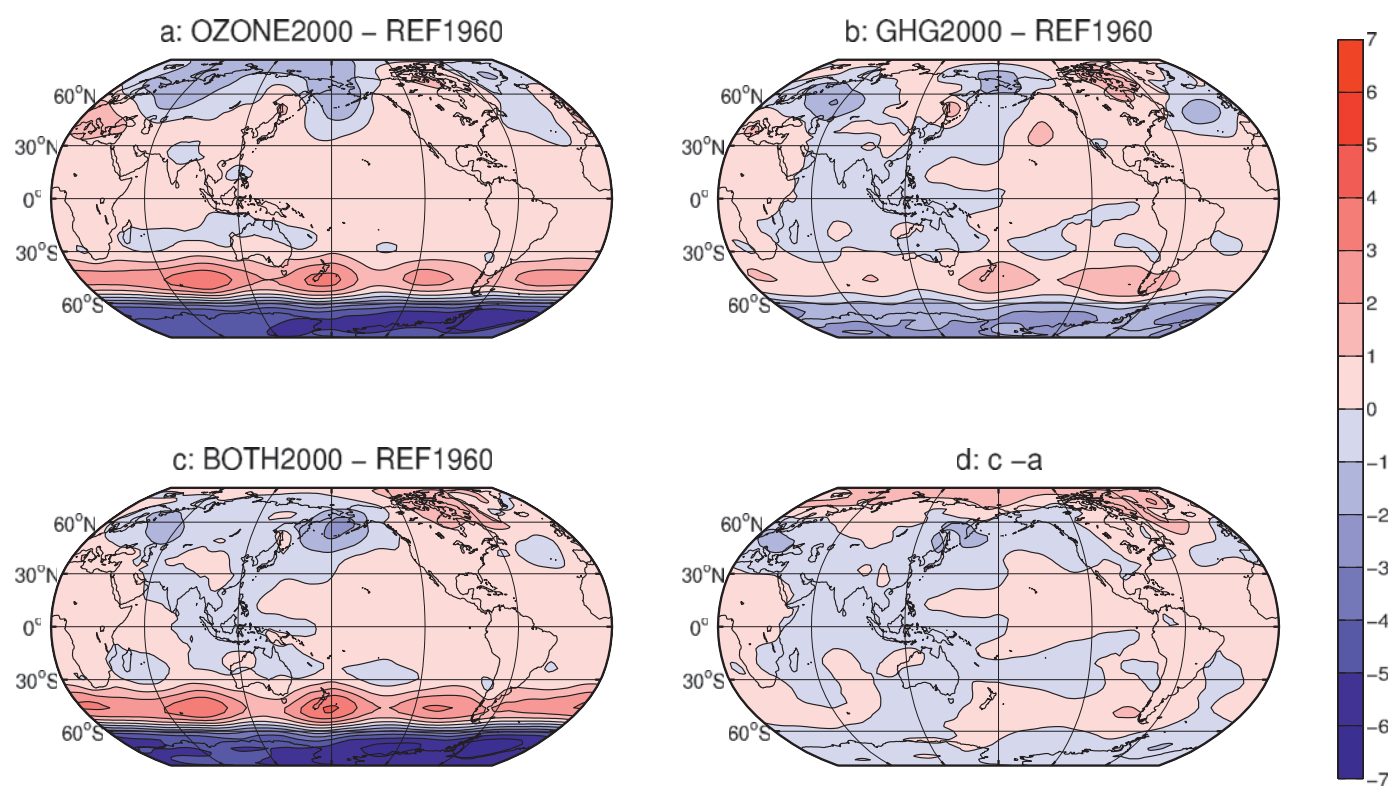

FIG. 7. As in Fig. 2, but for SLP, with contour interval of $1 \mathrm{hPa}$. All panels are Robinson projections, extending from $85^{\circ} \mathrm{S}$ to $85^{\circ} \mathrm{N}$.

Finally, the dominant surface signature of the effects of ozone depletion on the midlatitude circulation is well captured in the sea level pressure fields, which we show in Fig. 7, for direct comparison with previous studies, notably DP09. Notice again how the signal caused by stratospheric ozone depletion (Fig. 7a) is much larger than the one caused by greenhouse gas increases and the accompanying SST changes (Fig. 7b). In terms of the SAM, computed simply as the zonal mean sea level pressure difference between $45^{\circ}$ and $60^{\circ} \mathrm{S}$ (Marshall 2003) over DJF, the response for the OZONE2000 integration is $-6.6 \mathrm{hPa}$, in contrast with a mere $-2.4 \mathrm{hPa}$ for the GHG2000 integration. Note also how the SLP response in the integration with all the forcings is far from linear, in that Fig. 7d is quite distinct from Fig. 7b.

With regard to the GHG2000 integration, one might ask why the response in the Southern Hemisphere is stronger, and more annular in character, than the one in the Northern Hemisphere (see Fig. 7b), given that no ozone hole is specified in that integration. The cause for this, it so happens, is the Hadley Centre SSTs that we have been using. To demonstrate this, we have carried out a set of four integrations, identical to the ones described in Table 1, but with the SSTs from Hurrell et al. (2008), which are also based on observations, similarly averaged over 17-yr periods centered on 1960 and 2000. The results of those integrations are shown in Fig. 8.

First, notice that the response to ozone depletion (Fig. 8a) is, again, much stronger than the one due to increased greenhouse gases and SSTs (Fig. 8b) and dominates the combined response (Fig. 8c): this confirms the key finding of this study. Second, notice how sensitive the GHG2000-REF1960 response is to the choice of SSTs: the large difference between Figs. 7b and $8 \mathrm{~b}$ is, in fact, easily understood from Fig. 1 of Hurrell et al. (2008), where it is shown that much of the difference between the two sets of SSTs is in the SH high latitudes and has a zonally symmetric character. Third, to clarify the relative roles of SSTs and greenhouse gas increases, we have performed an additional model integration with only the SSTs changed to the year 2000 while the greenhouse gas concentrations (in addition to the ozone field) are kept constant at 1960 levels. In that case, the SLP response (Fig. 8d) is very similar, in the Southern Hemisphere, to the one in Fig. 8b, indicating that the SSTs are the key players. Fourth, we wish to emphasize that Fig. 8d is also very similar to Fig. 1e of DP09, as one might expect, since they are obtained using the same model (CAM3) and the same SST forcing (Hurrell et al. 2008), the only difference being that we are here integrating in time-slice mode, whereas DP09 used transient forcings.

This last comparison serves as a strong validation of our model integrations, in that we are able to reproduce previously published results. And, for the reader who may have gotten lost in the details of the SST discussion, we spell out the key point of this whole exercise: the model response to SSTs is quite sensitive to the dataset one chooses, but the model response to ozone depletion is very robust. 

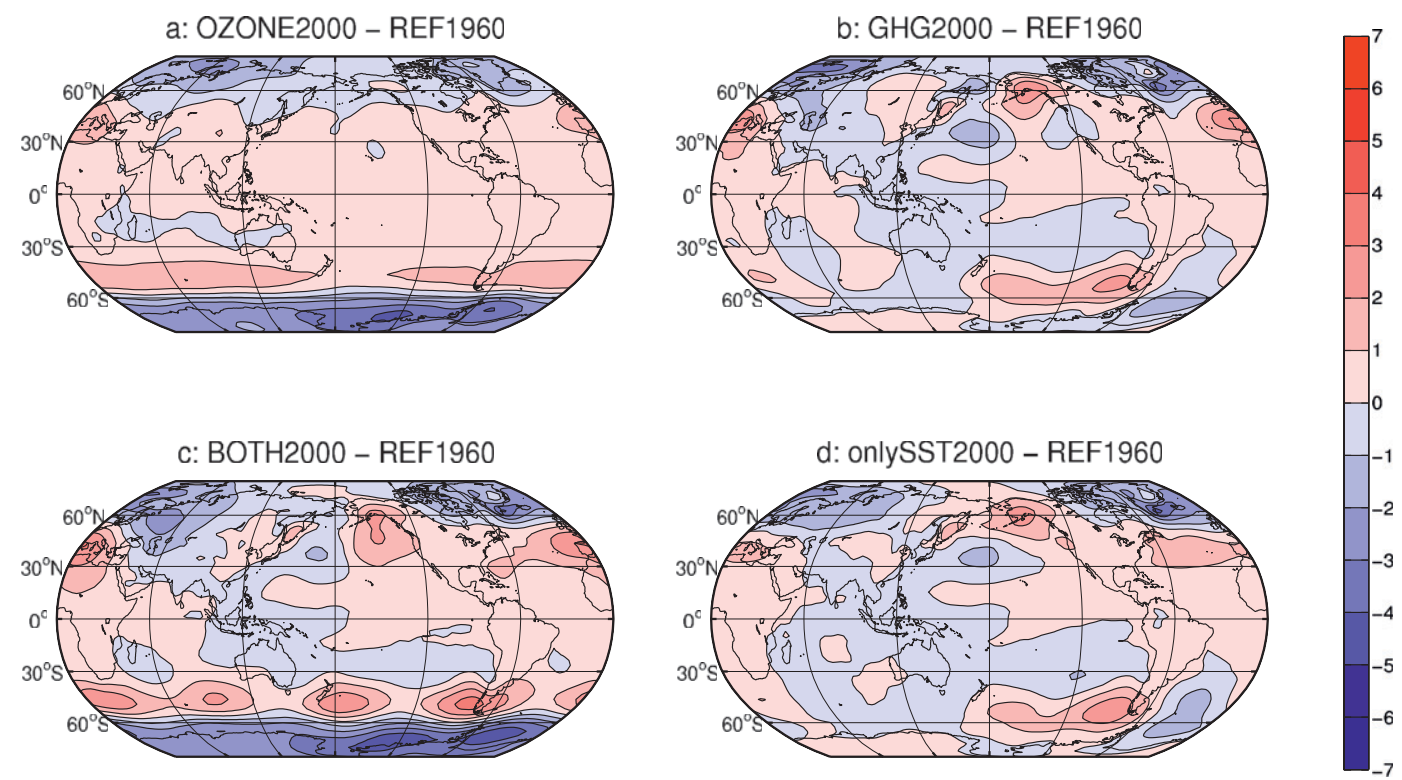

FIG. 8. (a)-(c) As in Fig. 7, but for model integrations with SSTs from Hurrell et al. (2008). (d) Response to SST changes alone.

\section{c. Hadley cell and hydrological response}

Having demonstrated the dominant impacts of stratospheric ozone depletion on the high- and midlatitude circulations, we next show that its impacts extend to the tropical circulation, notably to the Hadley cell. Following $\mathrm{Hu}$ and $\mathrm{Fu}$ (2007) and Johanson and $\mathrm{Fu}$ (2009), we compute the mean meridional mass streamfunction $\psi$ using the following expression:

$$
\psi(\phi, p)=\frac{2 \pi a \cos \phi}{g} \int_{0}^{p}[v] d p^{\prime},
$$

where $\phi$ is latitude, $p$ pressure, $[v]$ the zonal mean meridional wind, $a$ the radius of the earth, and $g$ the gravitational acceleration. The DJF differences in $\psi$ between the REF1960 integration and the ones with various forcings are shown in Fig. 9.

In all cases the response consists of a poleward expansion of the cell, but when stratospheric ozone depletion is present, the poleward shift is greatly amplified. To quantify the magnitudes of the shift, we define the edge of the Hadley cell as the latitude where $\psi=0$ at $500 \mathrm{hPa}$ in the SH. For the OZONE2000 integration this latitude shifts poleward by $1.0^{\circ}$, compared to only $0.5^{\circ}$ for the GHG2000 integration and $1.2^{\circ}$ for the BOTH 2000 integrations. These numbers are in good agreement with those of the recent CCCMVal2 model intercomparison, and with those of the CMIP3 models that included ozone depletion (see Table 2). Again, we note that the model response is not quantitatively linear, as can also be seen directly by contrasting Figs. 9b and $9 \mathrm{~d}$.
Furthermore, we find that only in the OZONE2000 and BOTH2000 integrations is the poleward shift of the Hadley cell larger than the interannual variability. This is illustrated in Fig. 10, where the DJF time series for the edge of the Hadley cell are shown. In each panel in Fig. 10 the black curve indicates the REF1960 integration, and the colored curve the forced integration. In Figs. 10a and $10 \mathrm{c}$, where stratospheric ozone depletion is present, the curves for the reference and forced integrations are well separated, showing a robust poleward shift of about $1^{\circ}$ of latitude. In the GHG2000 integration (Fig. 10b), while a suggestion of a poleward shift is present, the reference and forced time series are largely overlapping. Note, finally, that the JJA time series (shown in the right column) show no response to forcings: for ozone depletion this is exactly as expected, but for the GHG2000 integration this highlights how small the SH circulation response to observed greenhouse gas and SST forcings is, at least over the period 1960-2000 as computed by our model.

To establish the causality link between the poleward Hadley cell expansion and the depletion of stratospheric ozone, we now relate the latitude of the edge of the Hadley cell to the position of the midlatitude jet. In DJF, the $\mathrm{SH}$ midlatitude jet is located around $45^{\circ} \mathrm{S}$, and is largely driven by synoptic-scale eddies. Such eddies are able to affect the width of the Hadley cell, as shown by a number of studies (Held and Phillipps 1990; Kim and Lee 2001; Walker and Schneider 2006; Schneider and Bordoni 2008). In Fig. 6b, the latitude of the edge of the Hadley cell is plotted as a function of the latitude of the maximum zonal winds at $850 \mathrm{hPa}$ : notice the excellent 

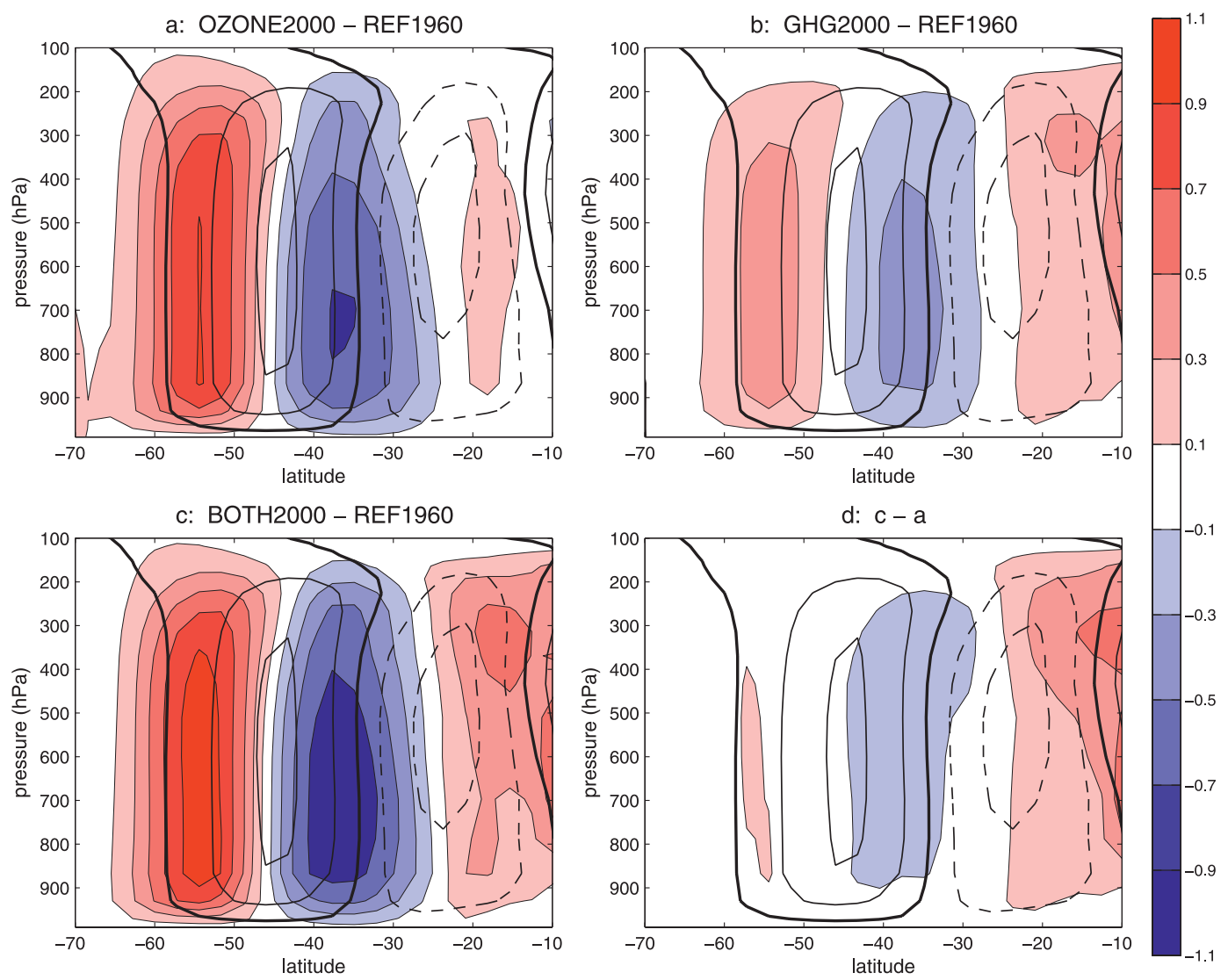

FIG. 9. As in Fig. 2, but for the mass streamfunction. In all panels the contour interval is $0.2 \times 10^{10} \mathrm{~kg} \mathrm{~s}^{-1}$. Black contours show the zonal mean, time mean, DJF mass streamfunction for the REF1960 integration, with contour intervals of $2 \times 10^{10} \mathrm{~kg} \mathrm{~s}^{-1}$, negative contours dashed, and a thicker zero contour.

correlation of these two quantities, both on interannual time scales (small dots) and in terms of mean climate response to the imposed forcing (large dots). In JJA a much weaker (if any) correlation is expected, and none is found in our model integrations (see Fig. 6e).

We finally turn to the effects of stratospheric ozone depletion on the hydrological cycle in the SH. We first consider the precipitation $P$ and the evaporation $E$, in the usual $P-E$ combination. For DJF, the model $P-E$ responses are shown in Fig. 11a: notice how the response in the presence of ozone depletion (blue and green curves) in roughly twice as large as the one due to greenhouse gas increases alone (red curve). Furthermore, the response consists of a poleward shift in the latitude of the $P-E=0$ line, leading to a broadening of the SH dry zone, and it directly accompanies the poleward shift of the midlatitude jet. To illustrate this, we show in Fig. 11b the zonal mean, zonal wind response at $850 \mathrm{hPa}$. Note how the $P-E$ responses mirror the midlatitude jet responses to a very large degree.

The $P-E$ response is also directly related to the expansion of the Hadley cell. Analyzing scenario integrations for future climates in the CMIP3 archive, Lu et al. (2007) have shown that trends in the edge of the Hadley cell (defined as the latitude where $\psi=0$ at $500 \mathrm{hPa}$ ) correlate very strongly with trends in the boundary of the dry zones (defined as the latitude where $P-E=0$ in the $\mathrm{SH}$ ). We find this result in our integrations as well, as demonstrated by the large dots in Fig. 6c. Moreover, we note that the strong correlation between these two quantities is robust on interannual time scales, as shown by the small dots; this is perhaps not surprising, but we are not aware of this having been documented before from climate model integrations. Moreover, unlike the correlation between the jet latitude and the Hadley cell edge that nearly disappears in JJA (cf. Figs. 6b and 6e), the correlations between the Hadley cell edge and the $P-E=$ 0 latitude remain quite robust in austral winter (cf. Figs. 6c and 6f). Finally notice that the clustered large dots in Fig. 6f show no ozone depletion effects, as one would expect.

In DJF, the impacts of ozone depletion on the precipitation field are sufficiently strong that they can be seen without any need for zonal averaging. This is 
a: OZONE2000 (blue) and REF1960 (black)

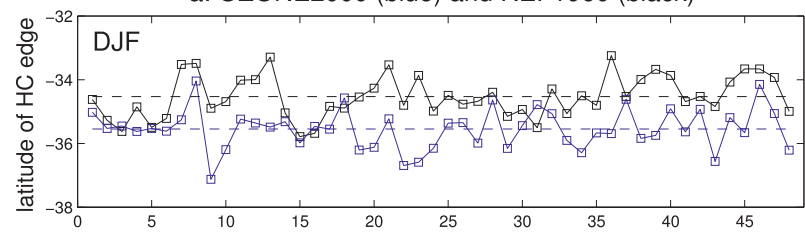

b: GHG2000 (red) and REF1960 (black)

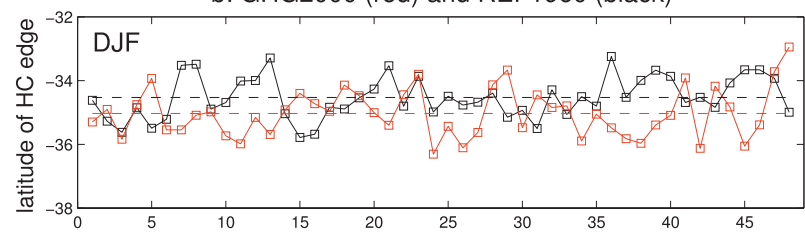

c: BOTH2000 (green) and REF1960 (black)

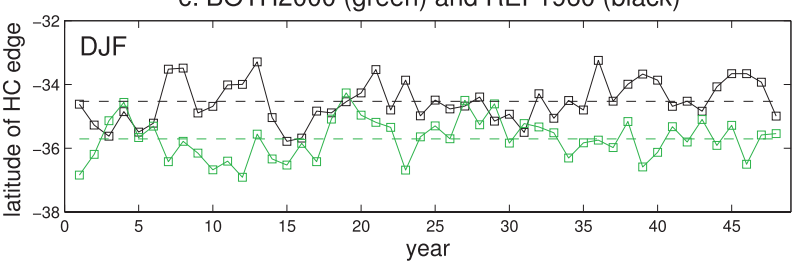

d: OZONE2000 (blue) and REF1960 (black)

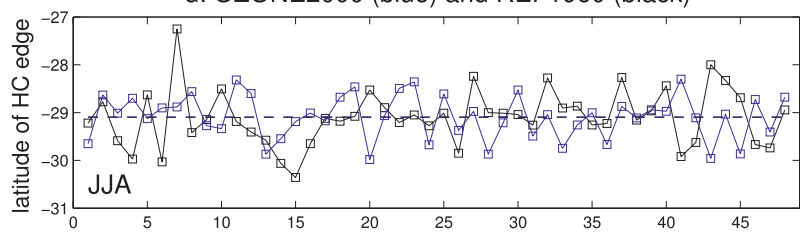

e: GHG2000 (red) and REF1960 (black)

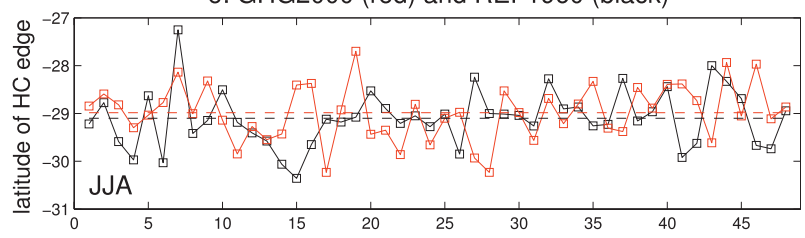

f: BOTH2000 (green) and REF1960 (black)

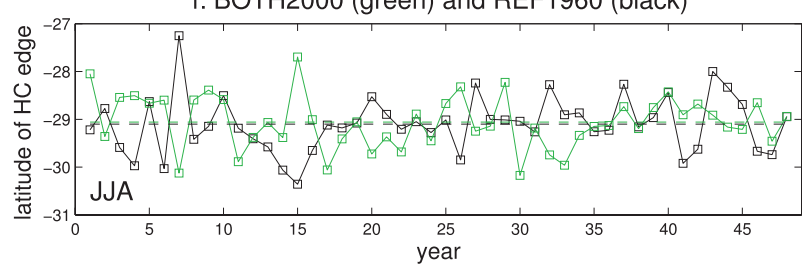

FIG. 10. As in Fig. 5, but for the edge of the Hadley cell in the SH. Note that the (left) DJF and (right) JJA axes for the ordinates are different.

illustrated in Fig. 12, where latitude-longitude maps of $P$ response are shown. Observe the appearance in Fig. 12a and $12 \mathrm{c}$, where ozone depletion is present, of two very clear, nearly parallel bands of precipitation changes (indicated by the black arrows): a zonally symmetric drying centered around $45^{\circ} \mathrm{S}$ (blue) and a concurrent moistening around $60^{\circ} \mathrm{S}$ (red). Of course, these changes accompany the poleward shift of the midlatitude jet, as shown in Fig. 11. A hint of similar changes in the GHG2000 integration can be seen in Fig. 12b, but these are much weaker than in the presence of stratospheric ozone depletion. Note also the nonlinearity of the $P$ response in Fig. 12d. Needless to say, the largest precipitation response occurs in the deep tropics. Interestingly a: $P$ - E response

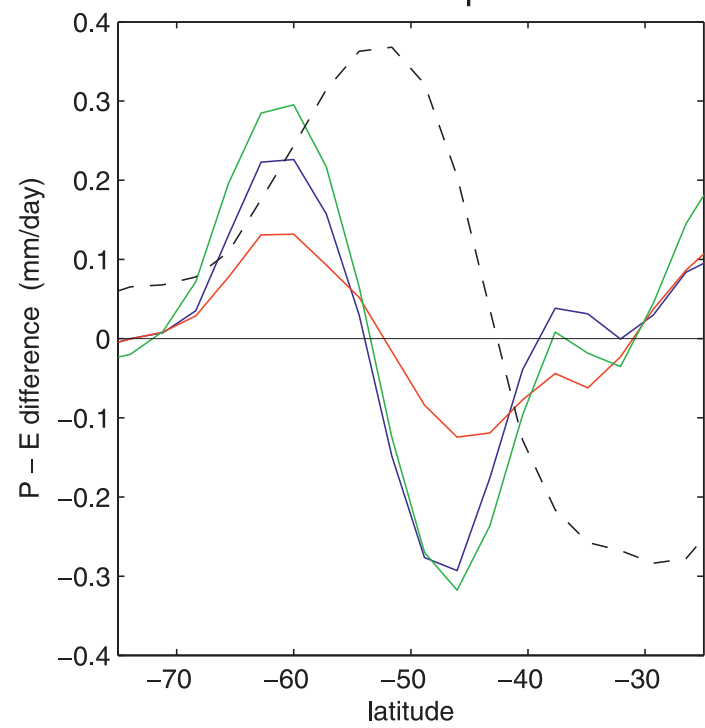

b: zonal wind response

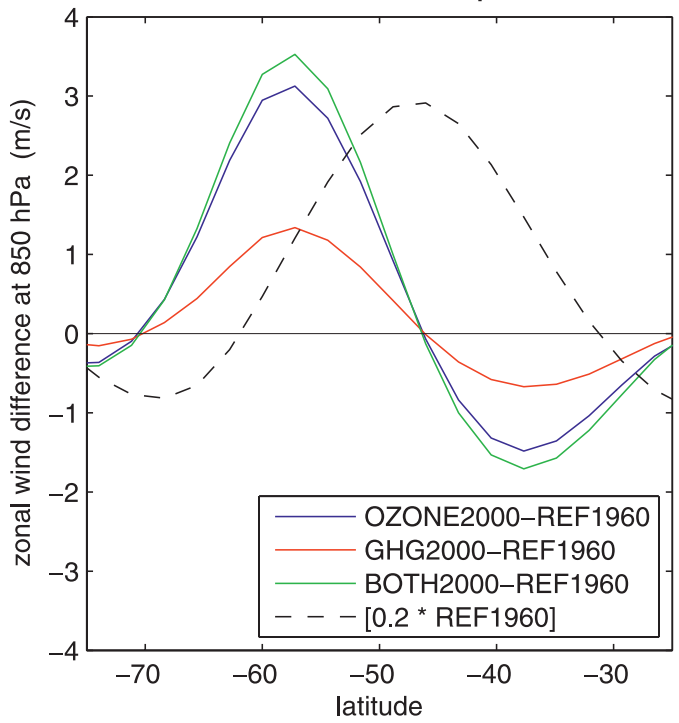

FIG. 11. Colored curves show the DJF response of the (left) zonal mean $P-E$ and (right) zonal wind at $850 \mathrm{hPa}$. For both panels the color coding is as per the legend on the right. Dashed curves indicate the corresponding quantities for the REF1960 integration, divided by a factor of 5 for clarity. 


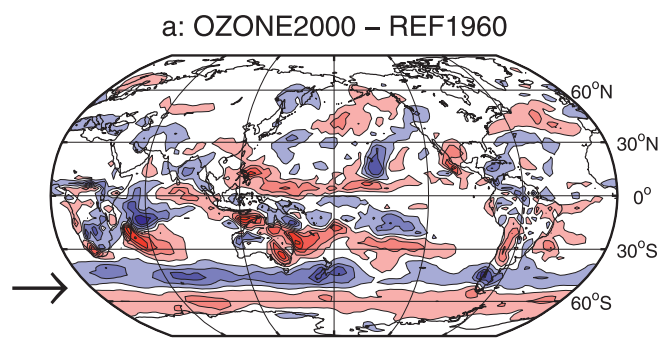

c: BOTH2000 - REF1960

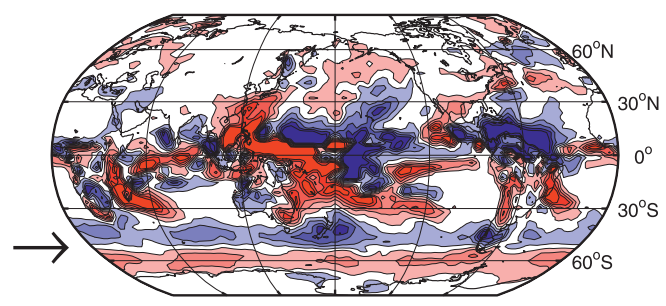

FIG. 12. As in Fig. 7, but for the precipitation $P$. In all panels the contour interval is $0.2 \mathrm{~mm}$ day $^{-1}$, and values above 1 are not contoured. The black arrows indicate the latitudes where the ozone depletion has a clear impact.

enough, some of it appears to be associated with ozone depletion; however, we are leery of drawing any conclusion from integrations with a single model, as the tropical precipitation is likely to depend greatly on convective and cloud parameterizations, which are highly model dependent. Further work, beyond the scope of the present study, is needed.

Finally, we emphasize that Fig. 12a may be directly compared with Fig. 11b of DP09, where their model response to atmospheric radiative forcing changes (from both greenhouse gas increases and ozone depletion), but in the absence of SST changes, is presented. Although that figure was obtained with greenhouse gas forcings that increase continuously between 1950 and 2000, and from an ensemble average of 10 model integrations, it compares remarkably well with the model response we compute in the OZONE2000 integration. It also shows a clear double band of precipitation anomalies in the $\mathrm{SH}$, of roughly the same magnitude as the one in Fig. 12a. Since greenhouse gas concentrations were not changed in our OZONE2000 integration, this comparison offers another independent validation that stratospheric ozone depletion is likely to have been responsible for the bulk of the circulation changes that have been observed in the SH over the second half of the twentieth century.

We conclude the presentation of our results by noting that while we have focused on the SH circulation changes that accompany the depletion of stratospheric ozone, we have also looked at the Northern Hemisphere responses. In brief, we have found no significant changes in all the quantities discussed above, for the integrations presented in Table 1, as one might perhaps have expected.

\section{Summary and discussion}

The goal of this paper has been to evaluate, quantitatively, the relative importance of stratospheric ozone depletion and greenhouse gas increases on the SH circulation. We summarize our findings in Fig. 13, where a number of key quantities describing the $\mathrm{SH}$ atmospheric circulation response to the different forcings are shown as a function of the calendar month. In Fig. 13a, for reference, we plot the SH polar cap SPARC ozone difference at $50 \mathrm{hPa}$ between the years 2000 and 1960: this is the key forcing in our model integrations and, as can be seen, is confined between August and December, peaking in October.

In all other panels in Fig. 13, the monthly difference between the REF1960 and the three forced integrations OZONE2000, GHG2000, and BOTH200 are indicated by the colored dots, in blue, red, and green, respectively. The vertical black lines show the standard deviation of the corresponding quantity, computed from yearly values over the $50 \mathrm{yr}$ of REF1960 integration; this allows us to directly visualize the size response compared the year-to-year variability. The statistical significance of the response (at the $99 \%$ confidence level) is assessed using a two-sided Student's $t$ test (von Storch and Zwiers 1999); statistically significant responses are indicated by large dots in each panel.

The immediate effect of the seasonal stratospheric ozone depletion (Fig. 13a) is to cool the lower-stratospheric polar cap (Fig. 13b), and thus raise the tropopause, as discussed above. There is a lag of about 1-2 months for the ozone depletion to be felt down at $100 \mathrm{hPa}$, which is also found in the CMIP3 and CCMVal model simulations (Son et al. 
a: ozone forcing [2000 - 1960]

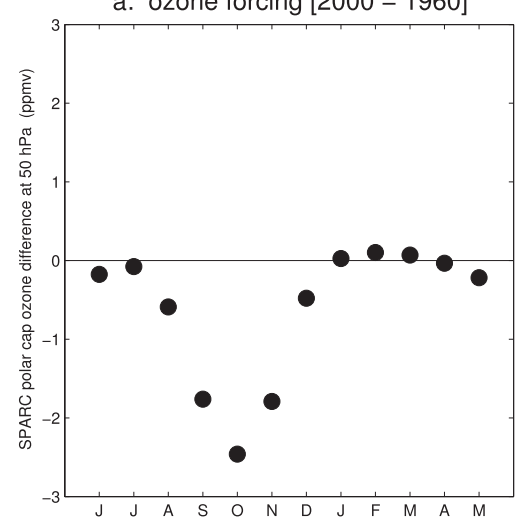

d: SAM response

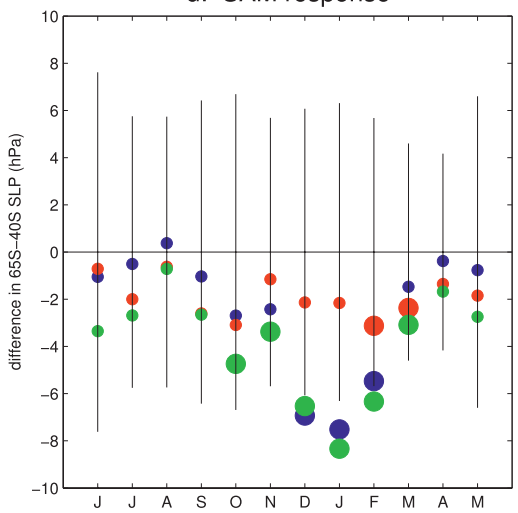

b: polar cap T response

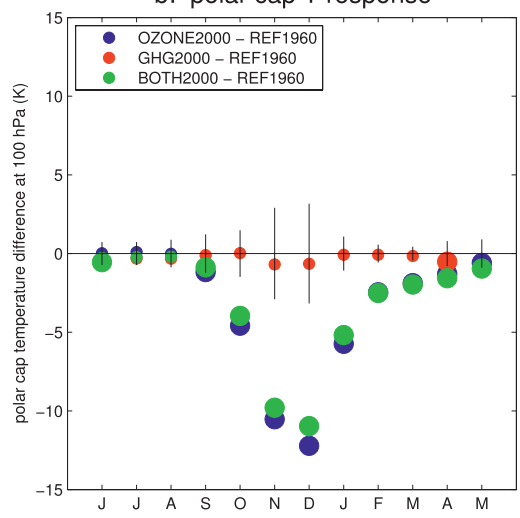

e: Hadley cell edge response

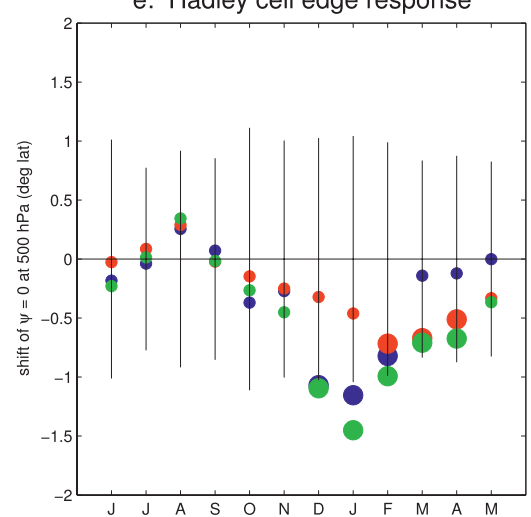

c: SH jet response

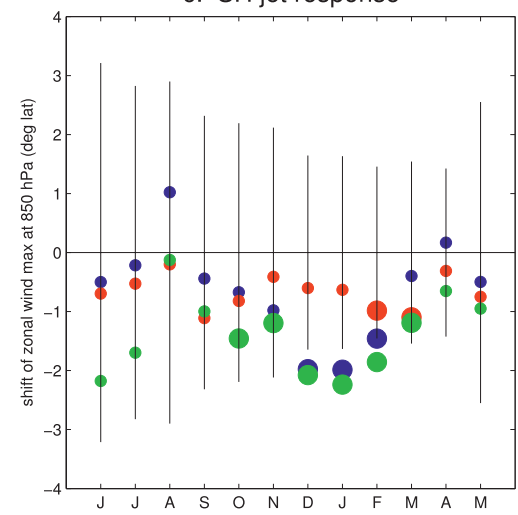

$f: P-E$ response

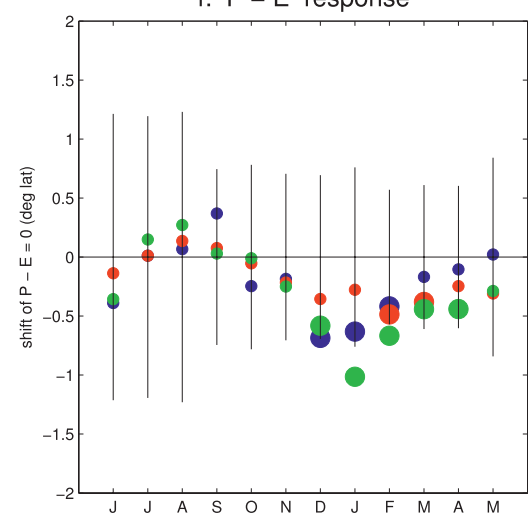

FIG. 13. Seasonal dependence of (a) the polar cap stratospheric ozone depletion and (b)-(f) the model response to different forcings. Vertical bars for each month indicate the interannual variability, defined as \pm 1 standard deviation from the 50-yr time mean. Large dots indicate responses that are statistically significant, at the $99 \%$ level, according to a $t$ test.

2008, 2010). This direct thermal effect results in the displacement of the midlatitude jet (Fig. 13c), a strengthening of the SAM (Fig. 13d), and a poleward shift of the Hadley cell edge (Fig. 13e) and of the $P-E=0$ latitude (Fig. 13f).

Note that the model response is greater than the interannual variability only when ozone depletion is present (blue and green dots) and, mostly, in DJF. In contrast, we find that the model response to greenhouse gas increases (with the accompanying warming of SST) is relatively small and, in nearly all cases, is not statistically significant (red dots). In addition, as can be seen in Figs. 13c-f, we find that the tropospheric circulation response is quantitatively nonlinear for all quantities examined in the study, with ozone depletion consistently dominating over increased greenhouse gases in DJF.

We wish to stress, as summarized in Table 2, that the results computed here with the atmosphere-only CAM model, are in good qualitative and even quantitative agreement with those obtained from analyzing the recent chemistry-coupled CCMVal2 model simulations and, to a large degree, the CMIP3 simulations that included ozone depletion. This gives us confidence that the results of our model are not unrepresentative outliers. The novelty in the set of integrations discussed here rests in that we are now able to ascribe most of the Southern Hemisphere climate change to polar stratospheric ozone depletion. This ability was lacking in earlier studies, since the forcings had not been examined in isolation.

The causality link between polar ozone depletion and circulation changes in the $\mathrm{SH}$ is very robust, yet the precise mechanisms remain unclear. For instance, several idealized studies have shown that thermal perturbations at or above the tropopause level are able to induce very robust shifts in the position of the midlatitude jet (Polvani and Kushner 2002; Williams 2006; Lorenz and DeWeaver 2007; Simpson et al. 2009), yet these have yielded a variety of different explanations. On the one hand, it has been suggested (Hartley et al. 1998; Thompson et al. 2006) that the stratosphere's effect on the tropospheric circulation may occur via a relatively simple "downward control" mechanism (Haynes et al. 1991). However, carefully controlled, numerical experiments with idealized models (Kushner and Polvani 2004) found that substantial eddy 
feedbacks that are not captured by downward control theory are at play. This was independently corroborated by Song and Robinson (2004), who further suggested that these feedbacks may be affected by planetary-scale waves, as further explored by Gerber and Polvani (2009).

On the other hand, several studies have attempted to understand the effects of stratospheric perturbations on synoptic-scale waves and individual baroclinic life cycles. Chen and Held (2007) have recently proposed that ozone-induced thermal perturbations alter the phase speed of synoptic-scale waves, and hence the latitudinal location of critical layers, resulting in a shift of the jet. In contrast, Simpson et al. (2009) propose that stratospheric thermal perturbations alter the direction of wave propagation, with a resulting shift in the wave-breaking region and a concomitant jet shift. Furthermore, both of these studies are difficult to reconcile with the earlier findings of Wittman et al. (2004, 2007), later confirmed and expanded upon by Kunz et al. (2009), who showed that the linear response to stratospheric thermal perturbations is largely irrelevant, and it is only at the nonlinear stage that one clearly observes the effects of stratospheric perturbations on baroclinic life cycle development. The bottom line is that much work remains to untangle these complex issues.

Beyond understanding how the position of the midlatitude jet is affected by ozone depletion, several other theoretical challenges are posed by the results of the present study, which are best illustrated by relationships among the varying components of the circulation uncovered in Fig. 6.

First, with reference to Fig. 6a, why is there no year-toyear correlation between polar cap temperature and jet position, but only a correlation in the multiyear time mean? As found within the context of the CCMVal and CMIP3 simulations (Son et al. 2010), models with a deeper ozone hole (and thus cooler polar caps) show larger poleward shifts of the jet. One would have naïvely believed this simple relationship would also exist on interannual time scales, but such is apparently not ${ }^{2}$ the case.

Second, the influence of stratospheric ozone depletion on the width of the Hadley circulation, which we have shown to be robust and which has been documented in CMIP3 models (Son et al. 2009a) and the CCMVal models (Son et al. 2008), remains to be understood at a fundamental level. Is the Hadley cell widening a merely passive response to the poleward shift of the jet? If this is

\footnotetext{
${ }^{2}$ We note that this lack of correlation is likely not due to the fact that our SSTs have been averaged over a 17-yr window. Preliminary analyses of integrations with transient SSTs indicate that DJF polar cap temperatures and jet positions are weakly correlated even when year-to-year variability in SSTs is present.
}

so, why does the Hadley cell shift by only $1^{\circ}$ when the jet shifts by roughly $2^{\circ}$ ? In other words, what sets the slope of the scatterplot in Fig. 6b? If that slope is a fundamental property of the atmospheric circulation, can one predict it?

Third, the relationship between the poleward edge of the Hadley circulation and the latitude where $P-E=0$ appears to be very robust, as seen in Fig. 6c; again, what sets this slope? The value for our four CAM integrations is roughly $1: 2$, that is, a $0.5^{\circ}$ shift in $P-E=0$ for a $1^{\circ}$ shift in $\psi=0$ at $500 \mathrm{hPa}$, in DJF. We are not aware of other studies that have shown this interannual correlation or reported the values of this slope. Lu et al. (2007) show the correlation of trends between these two quantities in the CMIP3 simulations of future scenarios (A1B, A2, and A1). From their Fig. 2, the slope between the two trends appears to be somewhat steeper than the one reported here (approximately $3: 4$ ), but we are quick to add that it is not immediately obvious that the interannual slopes and the slopes in the trends should have the same value (see Fig. 6a for a counter example).

Fourth, the correlation between the position of the jet and the edge of the Hadley cell appears to wane in JJA (Fig. 6e), as the position of the edge of the Hadley cell becomes nearly independent from the latitude of the jet maximum. This is rather surprising, given our current understanding of the interplay between the Hadley cell and the midlatitude, eddy-driven jet (Walker and Schneider 2006; Schneider and Bordoni 2008). In the winter season (JJA in the SH) eddy-momentum fluxes are usually stronger that in the summer season: to the degree that these fluxes control the edge of the Hadley cell, therefore, one would have expected a stronger correlation in JJA than in DJF. A more detailed investigation is beyond the scope of this paper, but this puzzling result surely will need to be understood.

Fifth, note that while the edge of the Hadley cell and the midlatitude jet appear to become uncorrelated in JJA, the correlation between the edge of the Hadley cell and the latitude of $P-E=0$ remains very strong in that season. In fact the slope in Fig. 6f is closer to 1:1, roughly double that in DJF. Again, we are aware of no study that has either presented or attempted to explain these basic facts.

Finally, we return to the effects of stratospheric ozone on the SH circulation. To quantify the relative importance of ozone depletion and increasing greenhouse gases, we have focused in this study on the period 19602000, for which all the key forcings are known (to some degree) from observations. Over that period, as pointed out by Shindell and Schmidt (2004), the effects of ozone depletion and increasing greenhouse gases have added constructively and conspired to yield a relatively large poleward shift of the overall atmospheric circulation. 
The key finding of this study has been to show that ozone depletion appears to have been the dominant factor in the recent $\mathrm{SH}$ atmospheric circulation changes.

In the twenty-first century, however, as stratospheric ozone recovers to pre-1960 levels, the effects of ozone recovery will oppose those resulting from increasing greenhouse gases. The key question, of course, is: Which of these two will dominate? Simulations conducted by the recent CCMVal2 intercomparison indicate a near-total cancellation of the effects of greenhouse gas increases by the recovery of stratospheric ozone (Son et al. 2010), yielding insignificant trends in the latitudinal position of the midlatitude jet and the edge of the Hadley cell between 2000 and 2100. Such projections, however, are founded on incomplete knowledge of SSTs and radiative forcings. Furthermore, there is some evidence that model simulations that prescribe monthly mean zonal-mean ozone fields, as we have done here, might underestimate the tropospheric response to changes in polar ozone (Gillett et al. 2009; Waugh et al. 2009). Whether the recovery of stratospheric ozone will be able to cancel the effects of greenhouse gas increases remains an open question. Time will tell.

Acknowledgments. The work of LMP and DWW is sponsored, in part, by grants from the National Science Foundation, to Columbia University and The Johns Hopkins University, respectively. SWS is supported by a Discovery grant from the NSERC of Canada. The authors are grateful to Drs. Michael Previdi and Sarah Kang for useful comments on early drafts of this manuscript.

\section{REFERENCES}

Arblaster, J. M., and G. A. Meehl, 2006: Contribution of external forcings to southern annular mode trends. J. Climate, 19, 28962905.

Archer, C., and K. Caldeira, 2008: Historical trends in the jet streams. Geophys. Res. Lett., 35, L08803, doi:10.1029/2008GL033614.

Black, R., and B. McDaniel, 2007: Interannual variability in the Southern Hemisphere circulation organized by stratospheric final warming events. J. Atmos. Sci., 64, 2968-2975.

— — - , and W. Robinson, 2006: Stratosphere-troposphere coupling during spring onset. J. Climate, 19, 4891-4901.

Cai, W., and T. Cowan, 2007: Trends in Southern Hemisphere circulation in IPCC AR4 models over 1950-99: Ozone depletion versus greenhouse forcing. J. Climate, 20, 681-693.

— , P. H. Whetton, and D. J. Karoly, 2003: The response of the Antarctic Oscillation to increasing and stabilized atmospheric $\mathrm{CO}_{2}$. J. Climate, 16, 1525-1538.

Chen, G., and I. M. Held, 2007: Phase speed spectra and the recent poleward shift of Southern Hemisphere surface westerlies. Geophys. Res. Lett., 34, L21805, doi:10.1029/2007GL031200.

Collins, W. D., and Coauthors, 2006: The Community Climate System Model version 3 (CCSM3). J. Climate, 19, 2122-2143.
Deser, C., and A. Phillips, 2009: Atmospheric circulation trends, 1950-2000: The relative role of sea surface temperature forcing and direct atmospheric forcing. J. Climate, 22, 396-413.

Eyring, V., and Coauthors, 2006: Assessment of temperature, trace species, and ozone in chemistry-climate model simulations of the recent past. J. Geophys. Res., 111, D22308, doi:10.1029/ 2006JD007327.

—, T. G. Shepherd, and D. W. Waugh, Eds., 2010: SPARC Report on the Evaluation of Chemistry-Climate Models. SPARC Rep. 5, WCRP-132, WMO/TD 152, 434 pp.

Fogt, R. L., J. Perlwitz, A. Monaghan, D. Bromwich, J. Jones, and G. Marshall, 2009: Historical SAM variability. Part II: Twentiethcentury variability and trends from reconstructions, observations, and the IPCC AR4 models. J. Climate, 22, 5346-5365.

Fyfe, J., G. Boer, and G. Flato, 1999: The Arctic and Antarctic Oscillations and their projected changes under global warming. Geophys. Res. Lett., 26, 1601-1604.

Gerber, E., and L. Polvani, 2009: Stratosphere-troposphere coupling in a relatively simple AGCM: The importance of stratospheric variability. J. Climate, 22, 1920-1933.

Gillett, N., and D. W. J. Thompson, 2003: Simulation of recent Southern Hemisphere climate change. Science, 302, 273-275.

, J. F. Scinocca, D. A. Plummer, and M. C. Reader, 2009: Sensitivity of climate to dynamically-consistent zonal asymmetries in ozone. Geophys. Res. Lett., 36, L10809, doi:10.1029/ 2009GL037246.

Hack, J., J. M. Caron, G. Danabasoglu, K. W. Oleson, C. Bitz, and J. Truesdale, 2006: CCSM-CAM3 climate simulation sensitivity to changes in horizontal resolution. J. Climate, 19, 2267-2289.

Hartley, D. E., J. T. Villarin, R. X. Black, and C. A. Davis, 1998: A new perspective on the dynamical link between the stratosphere and troposphere. Nature, 391, 471-474.

Haynes, P. H., M. E. McIntyre, T. G. Shepherd, C. J. Marks, and K. P. Shine, 1991: On the downward control of extratropical diabatic circulations by eddy-induced mean zonal forces. J. Atmos. Sci., 48, 651-678.

Held, I., and P. Phillipps, 1990: A barotropic model of the interaction between the Hadley cell and a Rossby wave. J. Atmos. Sci., 47, 856-869.

$\mathrm{Hu}, \mathrm{Y}$., and Q. Fu, 2007: Observed poleward expansion of the Hadley circulation since 1979. Atmos. Chem. Phys., 7, 5229_ 5236.

Hurrell, J., J. J. Hack, A. S. Phillips, J. Caron, and J. Yin, 2006: The dynamical simulation of the Community Atmosphere Model version 3 (CAM3). J. Climate, 19, 2162-2183.

$\longrightarrow,-$ D. Shea, J. M. Caron, and J. Rosinski, 2008: A new sea surface temperature and sea ice boundary dataset for the Community Atmosphere Model. J. Climate, 21, 5145-5153.

Johanson, C. M., and Q. Fu, 2009: Hadley cell widening: Model simulations versus observations. J. Climate, 22, 2713-2725.

Karpechko, A. Y., N. P. Gillett, G. J. Marshall, and A. A. Scaife, 2008: Stratospheric influence on circulation changes in the Southern Hemisphere troposphere in coupled climate models. Geophys. Res. Lett., 35, L20806, doi:10.1029/2008GL035354.

Kim, H.-K., and S. Lee, 2001: Hadley cell dynamics in a primitive equation model. Part II: Nonaxisymmetric flow. J. Atmos. Sci., 58, 2859-2871.

Kunz, T., K. Fraedrich, and F. Lunkeit, 2009: Response of idealized baroclinic wave life cycles to stratospheric flow conditions. J. Atmos. Sci., 66, 2288-2302.

Kushner, P. J., and L. M. Polvani, 2004: Stratosphere-troposphere coupling in a relatively simple AGCM: The role of eddies. J. Climate, 17, 629-639. 
— I. M. Held, and T. L. Delworth, 2001: Southern Hemisphere atmospheric circulation response to global warming. J. Climate, 14, 2238-2249.

Lorenz, D. J., and E. T. DeWeaver, 2007: Tropopause height and zonal wind response to global warming in the IPCC scenario integrations. J. Geophys. Res., 112, D10119, doi:10.1029/ 2006JD008087.

Lu, J., G. Vecchi, and T. Reichler, 2007: Expansion of the Hadley cell under global warming. Geophys. Res. Lett., 34, L06805, doi:10.1029/2006GL028443.

Marshall, G. J., 2003: Trends in the southern annular mode from observations and reanalyses. J. Climate, 16, 4134-4143.

—, P. A. Stott, S. J. Turner, W. M. Connolley, J. C. King, and T. A. Lachlan-Cope, 2004: Causes of exceptional atmospheric circulation changes in the Southern Hemisphere. Geophys. Res. Lett., 31, L14205, doi:10.1029/2004GL019952.

Meehl, G. A., C. Covey, T. Delworth, M. Latif, B. McAvaney, J. F. B. Mitchell, R. J. Stouffer, and K. E. Taylor, 2007a: The WCRP CMIP3 multimodel dataset. Bull. Amer. Meteor. Soc., 88, 1383-1394.

- and Coauthors, 2007b: Global climate projections. Climate Change 2007: The Physical Science Basis. S. Solomon et al., Eds., Cambridge University Press, 747-845.

Nakicenovic, N., and Coauthors, 2000: Special Report on Emissions Scenarios: A Special Report of Working Group III of the Intergovernmental Panel on Climate Change. Cambridge University Press, 599 pp.

Perlwitz, J., S. Pawson, R. L. Fogt, J. E. Nielsen, and W. D. Neff, 2008: Impact of stratospheric ozone hole recovery on Antarctic climate. Geophys. Res. Lett., 35, L08714, doi:10.1029/ 2008 GL033317.

Polvani, L., and P. J. Kushner, 2002: Tropospheric response to stratospheric perturbations in a relatively simple general circulation model. Geophys. Res. Lett., 29, 1114, doi:10.1029/ 2001 GL014284.

Previdi, M., and B. G. Liepert, 2007: Annular modes and Hadley cell expansion under global warming. Geophys. Res. Lett., 34, L22701, doi:10.1029/2007GL031243.

Randel, W. J., and F. Wu, 2007: A stratospheric ozone profile data set for 1979-2005: Variability, trends, and comparisons with column ozone data. J. Geophys. Res., 112, D06313, doi:10.1029/2006JD007339.

Rayner, N. A., D. E. Parker, E. B. Horton, C. K. Folland, L. V. Alexander, D. P. Rowell, E. C. Kent, and A. Kaplan, 2003: Global analyses of sea surface temperature, sea ice, and night marine air temperature since the late nineteenth century. J. Geophys. Res., 108, 4407, doi:10.1029/2002JD002670.

Reichler, T., M. Dameris, and R. Sausen, 2003: Determining the tropopause height from gridded data. Geophys. Res. Lett., 30, 2042, doi:10.1029/2003GL018240.

Santer, B. D., and Coauthors, 2003: Contribution of anthropogenic and natural forcing to recent tropopause height changes. Science, 301, 479-483.

Schneider, T., and S. Bordoni, 2008: Eddy-mediated regime transitions in the seasonal cycle of a Hadley circulation and implications for monsoon dynamics. J. Atmos. Sci., 65, 915-934.

Sexton, D. M. H., 2001: The effect of stratospheric ozone depletion on the phase of the Antarctic Oscillation. Geophys. Res. Lett., 28, 3697-3700.
Shindell, D. T., and G. A. Schmidt, 2004: Southern Hemisphere climate response to ozone changes and greenhouse gas increases. Geophys. Res. Lett., 31, L18209, doi:10.1029/2004GL020724.

Sigmond, M., J. Fyfe, and J. Scinocca, 2010: Does the ocean impact the atmospheric response to stratospheric ozone depletion? Geophys. Res. Lett., 37, L12706, doi:10.1029/2010GL043773.

Simpson, I. R., M. Blackburn, and J. D. Haigh, 2009: The role of eddies in driving the tropospheric response to stratospheric heating perturbations. J. Atmos. Sci., 66, 1347-1365.

Son, S.-W., and Coauthors, 2008: The impact of stratospheric ozone recovery on the Southern Hemisphere westerly jet. Science, 320, 1486-1489.

—, N. F. Tandon, L. M. Polvani, and D. W. Waugh, 2009a: Ozone hole and Southern Hemisphere climate change. Geophys. Res. Lett., 36, L15705, doi:10.1029/2009GL038671.

— , and Coauthors, 2009b: The impact of stratospheric ozone recovery on tropopause height trends. J. Climate, 22, 429-445.

_ - and Coauthors, 2010: The impact of stratospheric ozone on Southern Hemisphere circulation changes: A multimodel assessment. J. Geophys. Res., 115, D00M07, doi:10.1029/2010JD014271.

Song, Y., and W. A. Robinson, 2004: Dynamical mechanism for stratospheric influences on the troposphere. J. Atmos. Sci., 61, 1711-1725.

Thompson, D. W. J., and S. Solomon, 2002: Interpretation of recent Southern Hemisphere climate change. Science, 296, 895-899.

_ J. M. Wallace, and G. C. Hegerl, 2000: Annular modes in the extratropical circulation. Part II: Trends. J. Climate, 13, 10181036.

_ J. C. Furtado, and T. G. Shepherd, 2006: On the tropospheric response to anomalous stratospheric wave drag and radiative heating. J. Atmos. Sci., 63, 2616-2629.

Trenberth, K., and Coauthors, 2007: Observations: Surface and atmospheric climate change. Climate Change 2007: The Physical Science Basis, S. Solomon et al., Eds., Cambridge University Press, 235-336.

von Storch, H., and F. Zwiers, 1999: Statistical Analysis in Climate Research. Cambridge University Press, $484 \mathrm{pp}$.

Walker, C., and T. Schneider, 2006: Eddy influences on Hadley circulations: Simulation with a idealized GCM. J. Atmos. Sci., 63, 3333-3350.

Waugh, D. W., L. Oman, P. A. Newman, R. S. Stolarski, S. Pawson, J. E. Nielsen, and J. Perlwitz, 2009: Effect of zonal asymmetries in stratospheric ozone on simulations of Southern Hemisphere climate. Geophys. Res. Lett., 36, L18701, doi:10.1029/2009GL040419.

Williams, G., 2006: Circulation sensitivity to tropopause height. J. Atmos. Sci., 63, 1954-1961.

Wittman, M. A. H., L. Polvani, R. Scott, and A. Charlton, 2004: Stratospheric influence on baroclinic lifecycles and its connection to the Arctic Oscillation. Geophys. Res. Lett., 31, L16113, doi:10.1029/2004GL020503.

_ A. J. Charlton, and L. M. Polvani, 2007: The effect of lower stratospheric shear on baroclinic instability. J. Atmos. Sci., 64, 479-496.

WMO, 1957: Meteorology-A three-dimensional science. WMO Bull., 6, 134-138.

WMO/UNEP, 2003: Scientific Assessment of Ozone Depletion: 2002. Global Ozone Research and Monitoring Project Rep. 47, World Meteorological Organization/United Nations Envionment Programme, Geneva, Switzerland, 498 pp. 